\title{
Régua intervalar como ferramenta analítica em Quatro Peças Breves para piano de Roberto Victorio
}

\author{
Interval Ruler as Analytic Tool in Quatro Peças Breves for piano by \\ Roberto Victorio
}

\author{
Edson Hansen Sant'Ana \\ Instituto Federal de Mato Grosso
}

Resumo: O objeto central deste texto circunscreveu-se em torno da análise intervalar de uma pequena composição para piano de Roberto Victorio chamada Quatro Peças Breves. É uma tentativa de ampliar teórico-analiticamente o alcance de aplicação da régua intervalar (Sant'Ana 2017) em outros repertórios pós-tonais. Em síntese, esta ferramenta é composta por três parâmetros - índice de distância intervalar (IDI), densidade intervalar por classe de altura (DICA) e localização da altura na oitava (LAO). Os três parâmetros buscam entender e medir a organização espacial das estruturas entre si - um estudo que avaliaria a menor e a maior densidade intervalo-harmônica em qualquer conglomerado acórdico como representação de um bloco sonoro com função de clímax sonoro.

Palavras-chave: Densidade real; Densidade significativa; Densidade sonológica.

\begin{abstract}
The central object of this text was circumscribed around the interval analysis of a small composition for piano of Roberto Victorio called Quatro Peças Breves. It is an attempt to theoretically-analytically expand the range of application of the interval ruler (Sant'Ana 2017) in other post-tonal repertoires. In summary, this tool is composed of three parameters - interval distance index (IDI), interval density by height class (DICA) and location of height in the octave (LAO). The three parameters seek to understand and measure the spatial organization of structures among themselves - a study that would evaluate the smallest and highest harmonic-interval density in any conglomerate as a representation of a sound block with a sonic climax function.
\end{abstract}

Keywords: Real density; Significant density; Sonological density. 
Régua intervalar como ferramenta analítica em Quatro Peças Breves para piano de Roberto Victorio

\section{Introdução}

A concepção teórica desta proposição foi formulada na tese de Sant'Ana (2017) sob o título de "A concepção intervalar de Almeida Prado: um estudo em três obras pós ruptura". Uma das expectativas futuras, na conclusão da tese, era, como intento principal, realizar o teste da régua intervalar em outros repertórios pós-tonais que não fossem as obras de Almeida Prado. Nos termos de uma poética de música contemporânea associada à música não tonal, como novo objeto analítico, escolheu-se a obra "Quatro Peças Breves" para piano de Roberto Victorio com fins de aplicar o IDI, o DICA e o LAO - os três parâmetros da régua intervalar.

Buscando compreender as proposições da ferramenta, denominada régua intervalar, apresento o índice de distância intervalar (IDI) e o índice de densidade intervalar por classe de alturas (DICA), os quais podem ajudar a compreender a afirmação do compositor de que era um "compositor muito tímbrico", conforme a segunda entrevista que o compositor concedeu à Adriana Moreira (Moreira, 2004, p. 76). Acrescentando também que, os parâmetros IDI e DICA conduziriam à valorização do local das alturas nas oitavas (LAO) (Sant'Ana 2017, p. 232-233).

O indice de distância intervalar (IDI), para ser entendido devidamente, passaria pela revisão da diferença entre o que é "intervalo musical" e o que é "intervalo físico não ocupado". Entendendo o "intervalo físico não ocupado" como intervalo real, seria possível verificar, como no exemplo abaixo (Fig. 1), a rarefação provocada pelo espaço não ocupado entre alturas simultâneas - a contagem aconteceria a partir da mesma concepção de medida por semitons na prática comum da música ocidental. Sendo assim, na própria régua intervalar seria possível identificar o ponto de densidade intervalar máxima (segunda menor) e/ou os espaços "não ocupados" (rarefeitos) captados no ambiente do total cromático (a partir de uma segunda maior, onde já existiria um "espaço não ocupado" de meio-tom).

Como exemplo, para compreensão desta diferenciação prática destes conceitos intervalares, na Figura 1, temos as notas Si2 e Dó3 (em semitom) e as notas Fáł3 e Sol3 (em semitom) como alturas sobrepostas distadas em pares de uma segunda menor (densidade máxima). Entretanto, poderia se observar, também, uma relação de intervalo real, ou seja, um tipo de espaços não ocupados que definiriam as alturas não ocupadas compondo uma rarefação sonora - uma 
MUSICA THEORICA Revista da Associação Brasileira de Teoria e Análise Musical 2019, v. 4, n. 2, p. 81-112 - Journal of the Brazilian Society for Music Theory and Analysis@ TeMA 2019 - ISSN 2525-5541

possibilidade de medição pelo conceito e princípio da densidade real como uma interpretação diferenciada do que seria o intervalo musical.

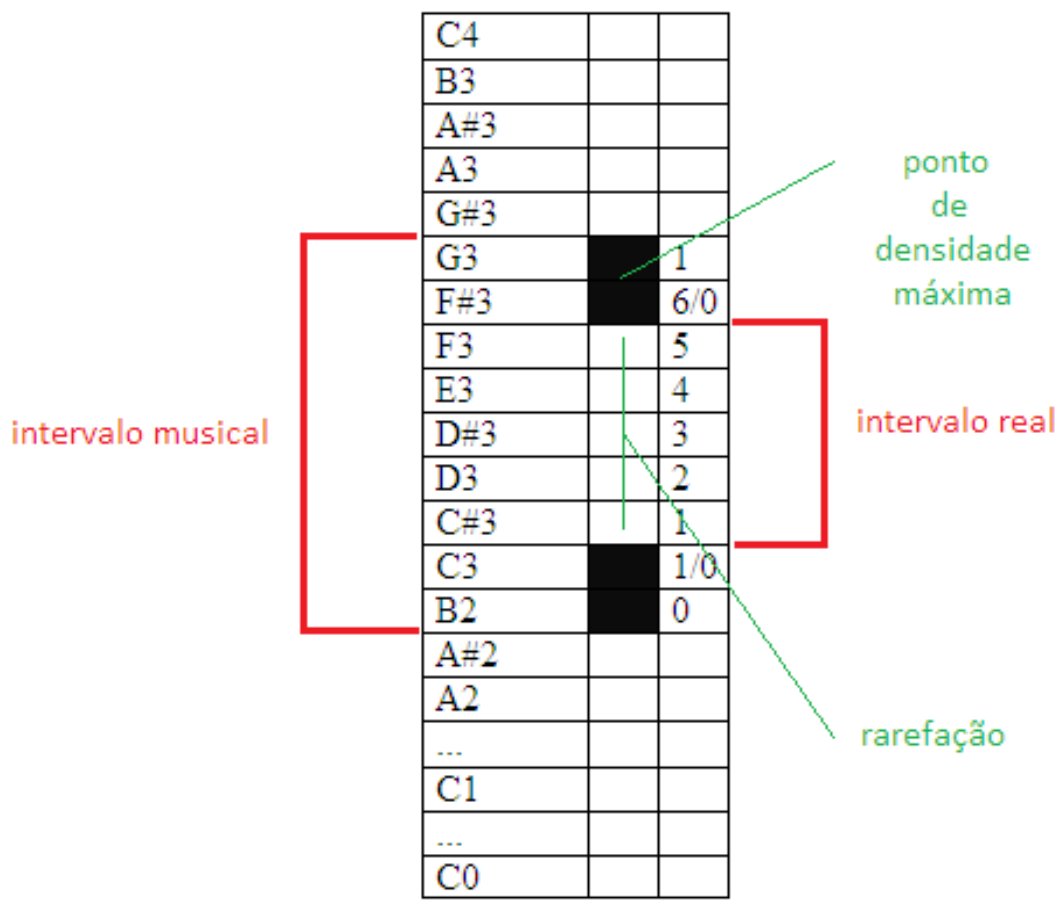

Figura 1: Régua intervalar demonstrando o intervalo musical e o intervalo real. Fonte: elaborado pelo autor (Sant'Ana 2017, p. 236)

Em suma, o índice de distância intervalar (IDI) leva em conta a distância real pelos pontos não ocupados na localização das alturas do total cromático. Com exceção da segunda menor, poderia dizer-se que em todas as outras distâncias intervalares musicais (intervalos fechados) existiriam os intervalos reais (intervalos abertos) ocorrentes entre dois sons. Neste sentido, haveria dois perfis que seriam passíveis de avaliação, medição e análise - os intervalos musicais e os 'intervalos reais'. Na prática, o IDI, como intervalo aberto seria o indicativo do intervalo real como um espaço não ocupado entre duas ou mais alturas. 
SANT'ANA, E. H. Régua intervalar como ferramenta analítica em Quatro Peças Breves para piano de Roberto Victorio

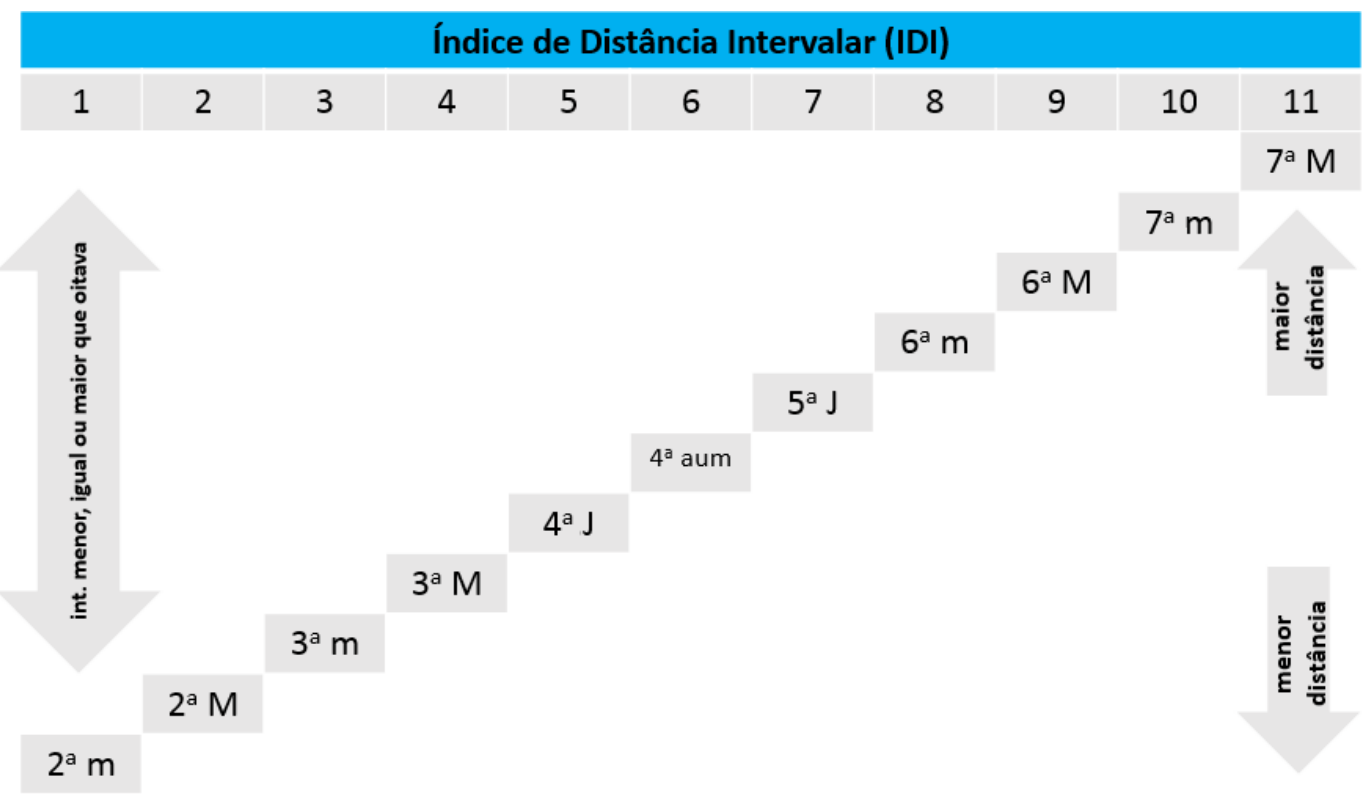

Figura 2: Índice de distância intervalar (IDI) é compreendido como qualquer intervalo igual ou maior que uma segunda maior até uma oitava; e/ou, maior, aqueles achados em outras oitavas audíveis no espectro da audição humana. Fonte: (Sant'Ana 2017, p.

238)

O IDI, como já dito, pode ser mensurado a partir de uma segunda maior neste intervalo musical há a ocorrência de um semitom como intervalo não ocupado (estrutura intervalar simultânea). Portanto, quando ocorresse a segunda menor, haveria, neste intervalo, a maior densidade referente à dureza máxima possível - ou seja, o intervalo de segunda menor como aquele de maior potência quanto ao aspecto de dissonância dura quando comparado aos outros intervalos possíveis e, tidos também como dissonância da mesma classe: sétima maior e nona menor -, entretanto, com IDI elevados (intervalos reais mais abertos). Entenda-se que este parâmetro trata de maneira diferenciada os três intervalos de dissonância dura - $2^{\underline{a}}$ menor, $7^{\underline{a}}$ maior e $9^{\underline{a}}$ menor. Quanto ao IDI, os referidos intervalos têm tamanhos e expansões diferentes conforme a Figura 2. O IDI, conceitualmente, poderia ser traduzido como um parâmetro que estudaria a densidade real de um intervalo.

Como segundo parâmetro desta régua, a densidade intervalar por classe de altura (DICA) consideraria qualquer intervalo, segundo a sua espécie, dentro de um espaço único e máximo do total cromático conforme o Mod 12 da Teoria dos Conjuntos de Allen Forte. Tal parâmetro também não dependeria da oitava que estivessem os intervalos estudados. Por exemplo, um Dó1-Si1 e/ou um Dó5-Si5, 
MUSICA THEORICA Revista da Associação Brasileira de Teoria e Análise Musical 2019, v. 4, n. 2, p. 81-112 - Journal of the Brazilian Society for Music Theory and Analysis @ TeMA 2019 - ISSN 2525-5541

ambos teriam a mesma importância, contanto que se reduzisse a análise intervalar a uma oitava.

De maneira tangencial, esse conceito se mostrou útil para este estudo, entretanto, considerou-se que a presente análise e o seu escopo teórico somente se atrelariam ao aspecto emergente da Teoria dos Conjuntos, limitando-se a não avançar nem utilizar a listagem das possibilidades dos conjuntos intervalares do Forte number. Para esta pesquisa interessou, introdutoriamente, somente a classificação dos intervalos da Set Theory, não como instrumento analítico, mas como parte do suporte conceitual que contribuiu para a construção teórica do que chamei de intervalo característico ${ }^{1}$ (Sant'Ana 2017, p. 203-204).

Quanto ao(s) intervalo(s) característico(s) a tensão é provocada por uma relação 'não estável' (relacionada a uma escuta física, "não cultural") que busca por meio da atratividade "estabilizar-se" ao eixo zero conforme a Figura 3 (o uníssono ou a repetição da oitava [azul]: "classe 0"). Assim, "os intervalos sobrepostos de uníssono e/ou de oitava justa são representados como semelhantes na sua função quanto à polaridadeConsequentemente, "As setas vermelhas pressionam o intervalo característico a se ajustar" (mesmo fenômeno da dissonância dura), "ou seja, buscar resolução à polaridade; não podendo ser ajustado, mantém-se em tensão à polaridade da oitava ou do uníssono (" 0 ")" (Sant'Ana 2017, p. 240).

Sant'Ana (2017, p. 240) propõe que as "cores nesta Figura 3 interpret[e]m a tensão (vermelho) e a atratividade da classe 0 (azul) em relação aos intervalos de segunda menor, sétima maior e nona menor, entendendo que a densidade intervalar máxima estará nos limites do intervalo característico de segunda menor." Assim também, "Os outros intervalos de sétima maior e nona menor est[ariam] em maior distância intervalar (IDI), porém situ[ria]am-se de forma satélite à polaridade da oitava (Costère 1954, 1962) e/ou classe de intervalo um (1), segundo Forte (1973) e Straus (2013)."

\footnotetext{
${ }^{1} \mathrm{O}$ intervalo característico é uma atribuição terminológica e conceitual utilizada em substituição do termo expressividade intervalar (cunhado pelo compositor Almeida Prado) - ambos os conceitos envolvem o estudo e a ocorrência da segunda menor, sétima maior e nona menor como intervalos representantes da dissonância dura.
} 
SANT'ANA, E. H. Régua intervalar como ferramenta analítica em Quatro Peças Breves para piano de Roberto Victorio

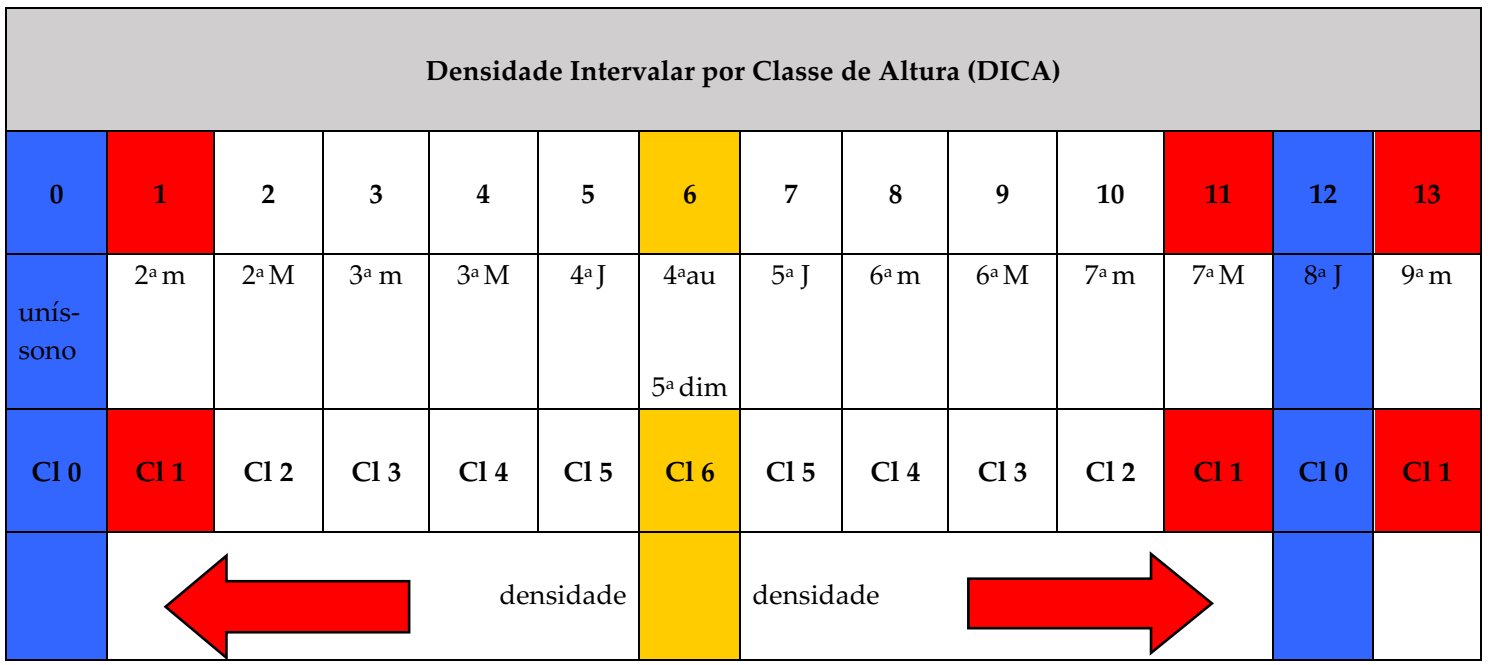

Figura 3: Classe de alturas segundo Forte (1973) e a correlação com o DICA (Densidade Intervalar por Classe de Altura). Fonte: (Sant'Ana 2017, p. 240)

Outra questão que se deve destacar é o fato de na Teoria dos Conjuntos não haver a designação de "classe 0 ". Ou seja, tal denominação é inserida por Sant'Ana (2017). "A Set Theory substitui as representações perceptivas e descritivas da dissonância e da consonância da prática musical comum por sua própria representação, que se denominou 'classe'." Deixando de se considerar "a 'classe 6' (trítono), todos os outros intervalos partem dos dissonantes para os mais consonantes (da esquerda ['classe 1'] para a direita ['classe 5'])." (Sant'Ana 2017, p. 204).

Como a Set Theory construiu as suas "classes de intervalos", em parte, baseadas no conceito de dissonância como relação primeira, as consonâncias secundarizadas (por exemplo, a "classe 5" na extrema-direita do quadro de Forte/Straus caracterizaram uma catalogação por hierarquia em ordem de importância físico-sonora. No Quadro 9 [figura 3] que trata da classe intervalar (interval class isso se deu primeiramente, em partes, pela própria organização intrínseca à série harmonica. Algumas ordens foram secundarizadas, como os intervalos da "classe 5" e da "classe 6". A oitava justa foi excluída das classes de intervalos. A proeminência seria dada à dissonância, como representante do intervalo potencial de dureza, o que conferiu ao repertório pós-tonal o seu alcance sonoro na estética da música do século $X X$.

Sendo a oitava excluída dessas seis classes, poder-se-ia subentender que ela seria uma possível "classe 0 " com correlação à classe de alturas/notas entre o '0' como Dó e o '12' como outro Dó na condição de oitava acima (reafirmando que ‘ 0 ' igual a Dó, ' 1 ' igual a Dó\# ou Réb... até o ‘11' igual ao Si [e um ‘12' igual ao Dó como hipotética oitava acima do ' 0 ']). Assim, a consonância seria 
MUSICA THEORICA Revista da Associação Brasileira de Teoria e Análise Musical 2019, v. 4, n. 2, p. 81-112 - Journal of the Brazilian Society for Music Theory and Analysis@ TeMA 2019 - ISSN 2525-5541

relativizada no corpo da teoria, prevalecendo uma ordem privilegiada da dissonância dura (classe 1) e de seus intervalos correlatos. É nesses termos que a interval class da Set Theory guardaria ligação com a série harmônica (Sant'Ana 2017, p. 204-205).

O DICA consiste de um parâmetro que, em certo sentido, salvaguardando-se das questões já apresentadas acima e, quanto ao fato de se buscar atender pela "classe 0 " os requisitos da ressonância e da Acústica, tal parâmetro consegue se equiparar plenamente ao projeto e à cultura da escuta ocidental. Assim, poderia dizer-se que o parâmetro DICA apreenderia o que se tem chamado de densidade significativa.

Como último e terceiro parâmetro, o local da altura na oitava (LAO) seria a ferramenta "que verifica em qual oitava a(s) altura(s) (nota e/ou intervalo) ocorreria(m). Como exemplo, um Dó seria verificado se pertenceria à primeira oitava (Dó1) ou à segunda oitava (Dó2)." Nestes termos, "esse parâmetro leva[ria] em conta a posição real de cada som, ou seja, o local do intervalo na sua oitava real [...]" quando seria considerado determinadas alturas. (Sant'Ana 2017, p. 241). Outro dado importante, que deve ser incluído na consideração da criação desta ferramenta seria o fato de, apesar de estar contido o problema da inarmonicidade quando se lidasse com os harmônicos no estudo sonológico, em um primeiro plano, o objetivo deste construto conceitual seria somente focar as relações dos intervalos de dissonância dura quando se preocupassem com os aspectos do timbre harmônico que, a princípio, sem excluir a inarmonicidade, ainda assim, seria mais ligado às relações de uma "corda ideal" 2 com base em "modelos teóricos".

O LAO busca compreender, analisar e avaliar as alturas que são definidas no total cromático. Este parâmetro visa facilitar o entendimento das "frequências existentes, como passíveis de escuta pelo sistema auditivo humano" (região grave, média e/ou aguda). Nesta perspectiva, trata-se de verificar a "região em que determinado intervalo ocorrerá, ou seja, de onde parte o seu reconhecimento enquanto som/altura em determinada oitava [...]". "[...] $\mathrm{O}$ peso e a massa provenientes de um Dó0 serão totalmente diferentes de um Dó3. Assim, a

\footnotetext{
2 A "corda ideal" tem base em "modelos teóricos" (Reblitz 1976; Goldemberg 2005) quando os autores discutiram o fenômeno da inarmonicidade. Este fenômeno estaria mais presente no som de cordas mais curtas encontradas em pianos com medidas menores (pianos de armário) do que em grandes pianos de concerto, tendo estes últimos, um menor grau de desvio por inarmonicidade, justamente, por possuírem cordas de tamanhos naturalmente maiores.
} 
SANT'ANA, E. H. Régua intervalar como ferramenta analítica em Quatro Peças Breves para piano de Roberto Victorio

abordagem e a análise do(s) intervalo(s) característico(s) farão considerável diferença levando-se em conta as regiões de cada oitava onde possa(m) de fato ocorrer (LAO)." Este parâmetro considera o "peso e a massa adensados ou não pela presença de harmônicos" que "tornar-se-ão mais ou menos evidentes dependendo do local de ocorrência na oitava (Sant'Ana 2017, p. 241).

Em suma, este parâmetro deve ser estudado em conjunto com as ferramentas da Sonologia que podem avaliar frequência, forma de onda e parciais (pares e ímpares; volumes individuais destas parciais; etc), associando esta análise musical às ideias da posição da oitava, do total cromático e dos sistemas musicais. Quanto ao parâmetro da LAO, este deveria ser sempre entendido como um estudo de densidade sonológica, consistindo de uma análise da natureza sonora e as suas representações musicais no total cromático.

Mesmo que se pense na associação de dois sons como ideia do intervalo musical, anteriormente, ao conceito destes dois sons dispostos como intervalos, é imprescindível a compreensão da natureza tridimensional do som individual - a nota musical - que é disposta pela composição de três eixos (razões) que são: a frequência (F), a intensidade $(G)$ e o tempo $(t)$. Assim, podemos pensar a altura musical como um objeto que possui uma densidade sonológica que deverá ser compreendida nas suas três dimensões.

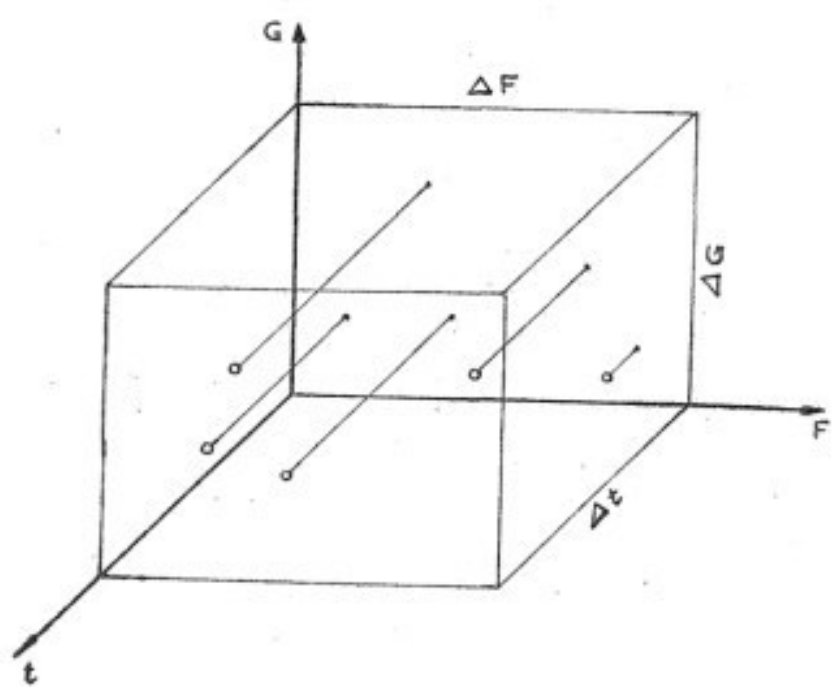

Figura 4: Uma das perspectivas da ilustração da tridimensionalidade de um som. G: intensidade; F: frequência; t: tempo. Fonte: (Xenakis 1992, p. 69) 
MUSICA THEORICA Revista da Associação Brasileira de Teoria e Análise Musical 2019, v. 4, n. 2, p. 81-112 - Journal of the Brazilian Society for Music Theory and Analysis @ TeMA 2019 - ISSN 2525-5541

Como expansão da representação tridimensional de um determinando som, veja-se a visualização destas dimensões de uma dada altura específica como amostra (ex.: Dó3).

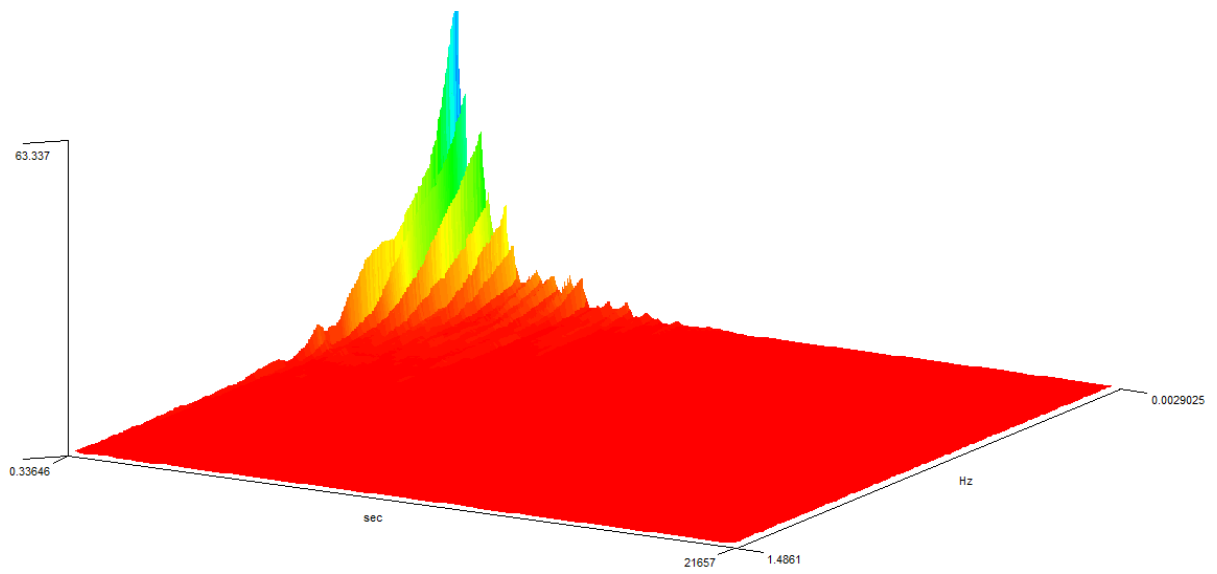

Figura 5: Representação tridimensional ([F], [t] e [G]) do Dó3 e das suas parciais. No setor mais colorido (verde, amarelo e alaranjado) é possível a visualização dos diferentes harmônicos e das suas amplitudes decrescentes a partir da ocorrência de cada parcial subsequente. Fonte: (Sant'Ana 2017, p. 248)

A forma de onda, como outra ferramenta, neste caso, capaz de evidenciar as alturas da escala cromática, como exemplo, nesta tessitura entre o Dó0 e o Dó1, poderia ajudar a mensurar a apresentação do decaimento gradual das alturas desse total cromático. Na Figura 6, a densidade diminui em função das notas mais agudas.

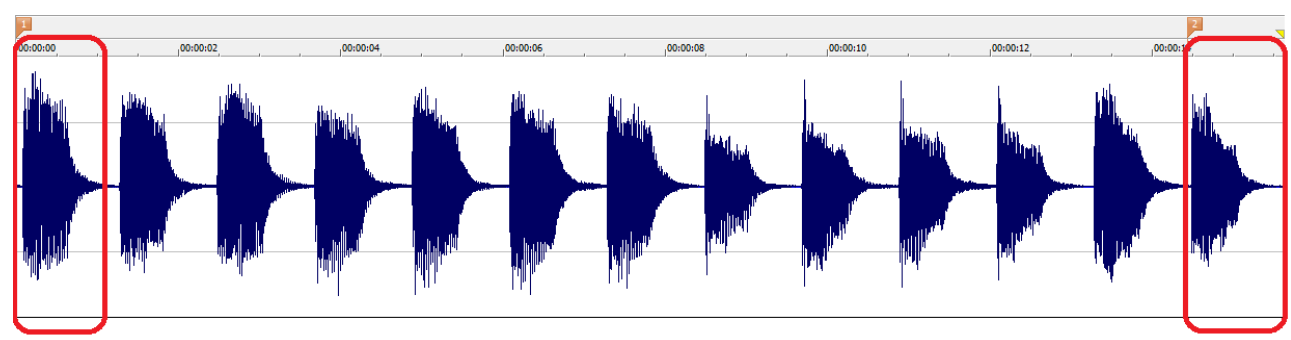

Figura 6: Forma de onda da escala cromática entre o Dó0 ao Dó1

As notas 'Dó', que aparecem comparadas e grifadas em vermelho (Dó0 e Dó1), indicam a perda de densidade sonora. Todas as notas, incluindo o Dó0 e o Dó1 (Dó¥0, Ré0, Ré\#, etc.), obtiveram as suas amplitudes sob velocity 100; daí, verificou-se um decaimento (decay) cada vez maior, conforme a forma de onda 
Régua intervalar como ferramenta analítica em Quatro Peças Breves para piano de Roberto Victorio

(Attack, Decay, Sustain e Release). ${ }^{3} \mathrm{O}$ decaimento é o enfraquecimento de certos harmônicos ${ }^{4}$ secundários que se arrefecem em função do tempo, quando as notas se tornam mais agudas. Observa-se também que algumas amplitudes dos primeiros harmônicos das notas mais agudas dessa amostra possuem decaimento não uniforme (em relação às outras notas) - isso se dá em função de alguma filtragem no sampleamento (caso do Sol0: oitavo som da amostra). Fonte: (Sant'Ana 2017, p. 243).

Como exemplos mais contrastantes, ao se comparar um Dó3 e um Dó7, as formas de onda destas referidas notas, de alguma forma, poderiam oferecer um desenho das diferenças na perspectiva da densidade sonológica.

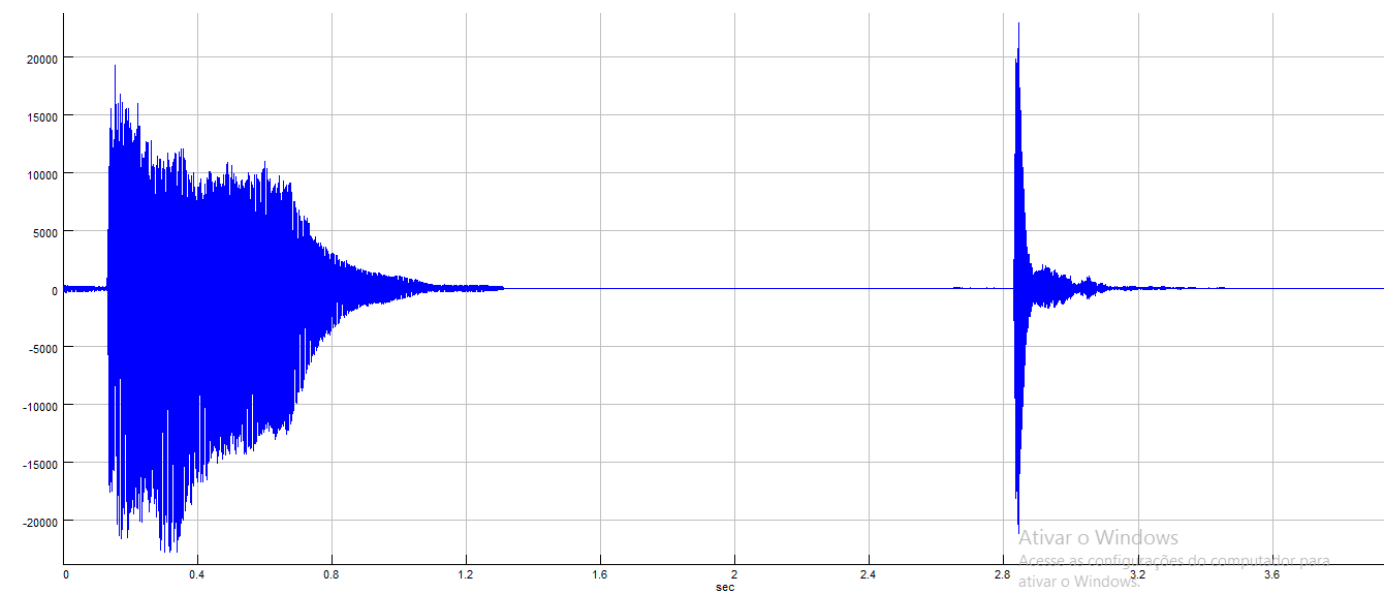

Figura 7: Comparativo do envelope ADSR entre o Dó3 e o Dó7 em apresentação consecutiva. Fonte: (Sant'Ana 2017, p. 245)

Apesar dos exemplos demonstrados acima, serem por meio de uma ocorrência consecutiva, quanto ao parâmetro LAO, o objetivo é poder desenvolver análises em duas alturas simultâneas - justamente o que se define como princípio fundamental do intervalo musical harmônico. O estudo teórico, aqui proposto, visaria poder ampliar a análise intervalar em associação a outros parâmetros que possam compor outros aplicativos e princípios da Sonologia e da

3 Attack, Decay, Sustain e Release: em português, ataque, decaimento, sustentação e relaxamento. Alguns textos trocam release por relax (a última fase do envelope).

4 “Quando as frequências dos componentes de um som são relacionadas de forma simples, como múltiplos inteiros da frequência fundamental, as componentes serão chamadas de parciais harmônicas ou somente harmônicos. Portanto, um som é harmônico quando existe uma relação múltipla e inteira entre as frequências e uma fundamental chamada de $f_{0}$ " (Ogasawara 2008, p. 13). 
MUSICA THEORICA Revista da Associação Brasileira de Teoria e Análise Musical 2019, v. 4, n. 2, p. 81-112 - Journal of the Brazilian Society for Music Theory and Analysis@ TeMA 2019 - ISSN 2525-5541

Acústica adentrando-se às questões e às possíveis respostas que acercariam a importância do intervalo harmônico na construção do timbre ${ }^{5}$ harmônico ${ }^{6}$ como uma entidade harmônica. ${ }^{7}$

Em síntese, os três parâmetros - IDI, DICA e LAO - são os componentes que perfazem o total operacional da régua intervalar. Respectivamente, estes três parâmetros podem viabilizar o estudo analítico de qualquer conglomerado acórdico tonal ou pó-tonal no âmbito do total cromático. Em síntese, estes parâmetros podem ser traduzidos, respectivamente, como densidade real, densidade significativa e densidade sonológica.

\section{Quatro Peças Breves - uma descrição inicial da obra}

Estruturalmente, em números de compassos, as peças desta composição estão assim dispostas:

\footnotetext{
5 “O conceito de timbre está relacionado à resposta perceptiva subjetiva a qualidades do tom que permitem a identificação de sua fonte. Timbre é muito mais difícil de caracterizar do que intensidade percebida ou altura devido ao fato de ser um fenômeno bastante diverso. Não há uma escala unidimensional - tal como grave/agudo para altura - postulada para timbre, pois parece não existir um par simples de opostos entre os quais pode-se estabelecer uma escala." (Caetano 2006, p. 38).

${ }^{6}$ Dessa maneira, a compreensão da importância do intervalo e a sua relação com o timbre passa por uma revisitação histórica do que seriam as organizações harmônicas na estética da escola francesa em fins do século XIX. Compreender a linha genealógica do possível surgimento do conceito "timbre harmônico a partir da seleção de determinadas alturas e intervalos na estrutura acórdica, para que no total cromático, pudesse evidenciar certos harmônicos por meio da ressonância dos tipos sonoros como produtos variáveis de cor, tal estudo, passaria, inicialmente, pela consideração de estruturas harmônicas em que o grau de nona é mais evidenciado, como acontece na obra de Emmanuel Chabrier (1841-1894), na abertura da ópera cômica Le roi malgré lui (1887). É muito provável que Erik Satie (1866-1925) tenha escutado tais procedimentos em Chabrier e tenha utilizado em Le Fils des Etóiles os blocos paralelos de harmonias sob uma base de superposição intervalar." (Sant'Ana 2017, p. 40).

Didier Guigue em seu livro "Estética da Sonoridade" faz menção nos termos de "harmoniastimbre" escrevendo que "[... as referências comuns à herança musical francesa, um universo de “harmonias-timbre" [...]" (Guigue 2011, p. 147).

7 "Por entidade harmônica entende-se uma agregação intervalar (horizontal ou vertical, ou ambas ao mesmo tempo) de mais de dois elementos (notas, frequências), a qual institui alguma singularidade constitutiva do ponto de vista de sua estruturação (ou de sua estrutura harmônicointervalar. Duas notas são incapazes de constituir uma entidade; constituem, isto sim, um intervalo" (Menezes 2013, p. 42).
} 


\begin{tabular}{|c|c|c|c|}
\hline I & II & III & IV \\
\hline 22 & 13 & 21 & 40 \\
\hline
\end{tabular}

Tabela 1: Compassos das Quatro Peças Breves. Fonte: elaborado pelo autor

A construção rítmica nas peças I, II e IV, com excessão da peça III (integralmente sob a fórmula de compasso 5 por 4), são desenvolvidas, preferencialmente, com uma certa alternância de fórmulas de compasso. Na peça I, os seus 22 compassos são resumidos assim:

\begin{tabular}{|l|l|l|l|l|l|l|l|l|l|}
\hline 5 & 1 & 4 & 2 & & & 1 & 5 & 3 & \\
4 & 4 & 4 & 4 & & & 4 & 4 & 4 & \\
\hline & 2 & 3 & & & & & & & \\
& 4 & 4 & & & & & & & \\
\hline &
\end{tabular}

Tabela 2: Peça I e sua formulação de compasso. Fonte: elaborado pelo autor

A peça II, os seus 13 compassos, tem a seguinte organização:

\begin{tabular}{|l|l|l|l|l|l|l|l|l|l|}
\hline 4 & 2 & 3 & 2 & & 3 & & & & \\
4 & 4 & 4 & 4 & & 4 & & & & \\
\hline 5 & 3 & & \multicolumn{7}{|l|}{} \\
4 & 4 & &
\end{tabular}

Tabela 3: Peça II e sua formulação de compasso. Fonte: elaborado pelo autor

Sabendo que a peça III é toda desenvolvida com a fórmula de compasso 5 por 4, em continuidade, apresenta-se a peça IV, que estaria desenvolvida nos seus 40 compassos desta maneira:

\begin{tabular}{|c|c|c|c|c|c|c|c|c|c|}
\hline 4 & & 5 & 5 & 3 & 3 & 5 & 5 & 4 & 1 \\
4 & & 8 & 16 & 4 & 16 & 16 & 8 & 4 & 4 \\
\hline 5 & 6 & 3 & 5 & 4 & 8 & 2 & 6 & 2 & 3 \\
16 & 8 & 16 & 16 & 4 & 16 & 4 & 16 & 4 & 4 \\
\hline 4 & & & & & & & & & \\
4 & & & & & & & & & \\
\hline & & & 5 & 8 & 2 & 6 & 3 & 4 & 2 \\
& & & 8 & 16 & 4 & 8 & 16 & 4 & 4 \\
\hline
\end{tabular}

Tabela 4: Peça IV e sua formulação de compasso. Fonte: elaborado pelo autor

Como uma das estratégias de quebrar a regularidade rítmico-formal, Roberto Victorio imprime uma variação das fórmulas de compasso como se vê nas Tabelas 2, 3 e 4. Na construção do material musical há um desenvolvimento que visou quebrar a regularidade rítmica aplicando subdivisões do pulso da fórmula de compasso, hemíolas pontuais e/ou o uso da própria formulação de 
MUSICA THEORICA Revista da Associação Brasileira de Teoria e Análise Musical 2019, v. 4, n. 2, p. 81-112 - Journal of the Brazilian Society for Music Theory and Analysis @ TeMA 2019 - ISSN 2525-5541

compasso. Somando-se a essa ideia de confrontar, quase que de maneira livre, o pulso ternário (ex.: c. 3 por 4) quebrando a possível regularidade do binário e do quaternário. Este tipo de arrumação de tempo e de metro contribuiria com o fato desta composição poder ser elencada como pertencente ao repertório contemporâneo pós-tonal. Em alguns momentos o compositor flertaria com as estruturas do sistema tonal - principalmente, quando se observasse a linha de baixo da composição. Entretanto, entendendo-se que este procedimento, seria somente um background, para que, a posteriori pudesse efetuar as fricções intervalares de dissonâncias duras - onde a partir daí, o material seria vinculado, no seu todo, à estética pós-tonal. Como comprovação disso, poder-se-ia observar as relações harmônicas presentes no próximo exemplo. ${ }^{8}$
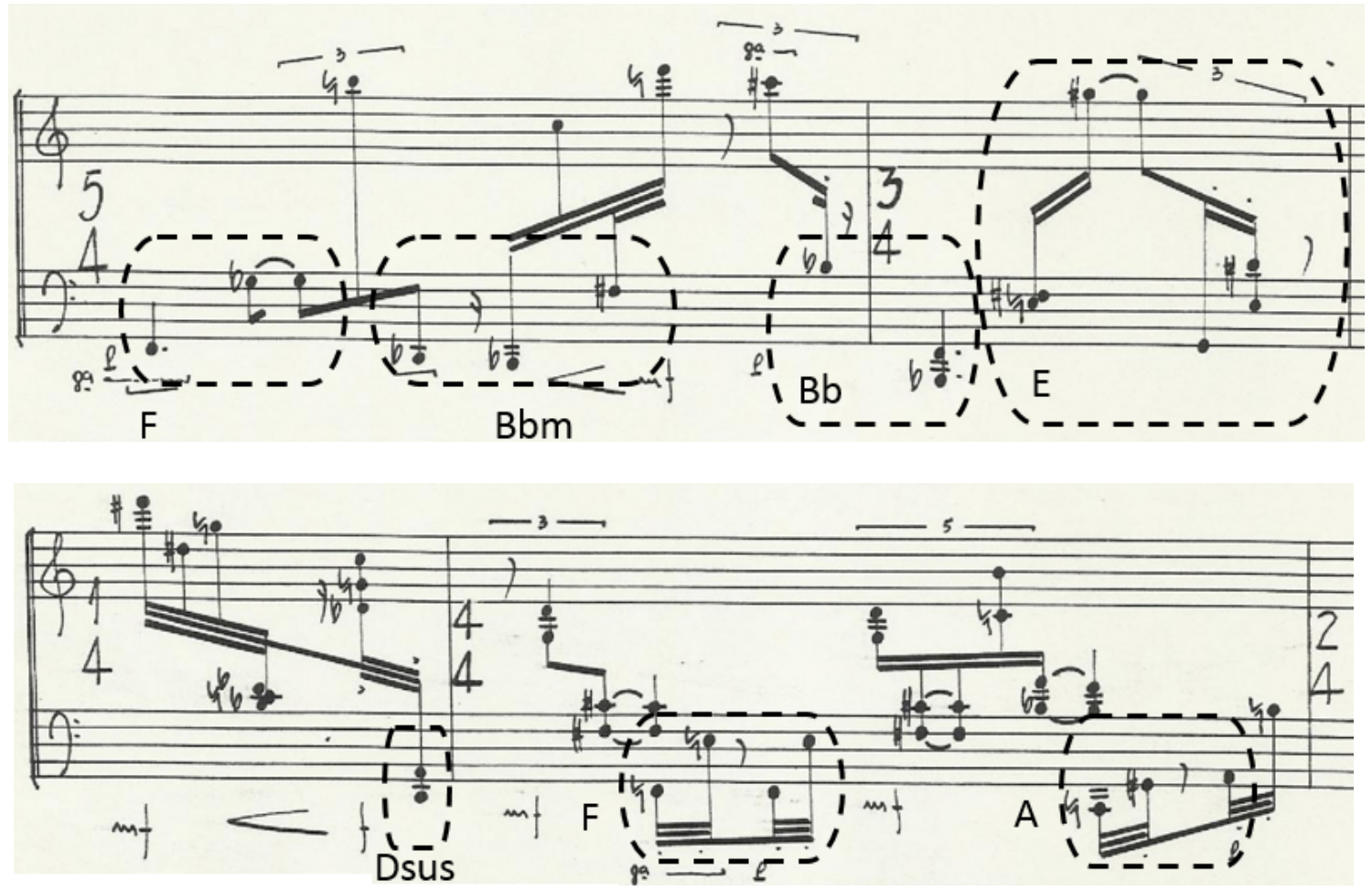

Exemplo 1: Relações harmônicas na linha de baixo na introdução da peça I. Fonte: elaborado pelo autor

Mesmo que não haja uma ocorrência constante e uniforme da tonalidade, como nos termos tradicionais da prática comum, verificou-se alguma preservação dessas relações - e/ou até uma existência de relações modais. Levando-se em

\footnotetext{
${ }^{8}$ Os exemplos analíticos dos Exs. 1-5, 7-8 e 10 utilizam a partitura original da obra.
} 
SANT'ANA, E. H. Régua intervalar como ferramenta analítica em Quatro Peças Breves para piano de Roberto Victorio

conta a sequência das harmonias comprovadas na Exemplo 1, poderia se fazer algumas deduções interpretativas dessa relação harmônica tonal conforme se verificaria na Tabela 5.

\begin{tabular}{|c|c|c|c|c|c|c|}
\hline $\mathrm{F}$ & $\mathrm{Bbm}$ & $\mathrm{Bb}$ & $\mathrm{E}$ & $\mathrm{D}\left(\operatorname{sem} 3^{\mathrm{a}} \cdot\right)$ & $\mathrm{F}$ & A \\
\hline $\mathrm{I}$ & $\mathrm{IVm}$ & IV & VII & VI & $\mathrm{I}$ & III \\
\hline $\mathrm{V}$ & Im & I & $>$ & Jdomina & iica & \\
\hline \multicolumn{3}{|c|}{ aproximação diatônica } & VII & VI & $\mathrm{I}$ & III \\
\hline \multicolumn{4}{|c|}{ sequenciação harmônica por relações de terças } & VI & I & III \\
\hline
\end{tabular}

Tabela 5: Hipóteses interpretativas do projeto harmônico da camada grave deste trecho da composição. Fonte: elaborado pelo autor

Como se afirmou anteriormente, mesmo que o compositor, no seu projeto harmônico, tenha intencionado algum relacionamento que estabelecesse nuances pertencentes ao modalismo e/ou ao tonalismo, o que de fato materializa-se nesta organização, seria a poética pós-tonal viabilizada pela arrumação intervalar. Devido à sobreposição das camadas médias e das superiores que seriam compostas de uma organização intervalo-harmônica que privilegiaria, o que tenho chamado de intervalos característicos - (segunda menor [primeira aumentada], sétima maior [oitava diminuta] e nona menor [oitava aumentada]) - aqueles intervalos de maior dureza sonora que, quando usados, intencionalmente, podem subverter a tonalidade, geralmente, vinculando, estético e poeticamente, a conjuntos estruturais harmônicos da pós-tonalidade.

\section{Da análise intervalar}

A partir daqui, para este estudo, a metodologia analítica passou a se preocupar unicamente com a ordenação e a organização intervalar na composição, ou seja, em buscar um entendimento que partiu das perspectivas que os três parâmetros (IDI, DICA e LAO) podem oferecer. Assim, as estruturas intervalares nas Quatro Peças Breves de Roberto Victorio passaram a ser estudadas do ponto de vista das densidades (real, significativa e sonológica).

Já na abertura da peça I ficaria evidente a ênfase contrapontística. Por este motivo, o IDI poderia ser interpretado por uma densidade real que se configuraria por uma considerável rarefação. É conveniente lembrar que o grau máximo de dureza do IDI, também chamado de densidade real máxima, pode ser percebido quando haveria uma ocorrência de segundas menores em disposição de clusters ou meio-clusters. Por outro lado, o IDI poderia ser 
MUSICA THEORICA Revista da Associação Brasileira de Teoria e Análise Musical 2019, v. 4, n. 2, p. 81-112 - Journal of the Brazilian Society for Music Theory and Analysis @ TeMA 2019 - ISSN 2525-5541

requisitado para estudar aquela estrutura harmônica que possuísse muitas sobreposições e conglomerados acórdicos sobrepostos também por espaços não ocupados - intervalos maiores que uma segunda menor.

Levando-se em conta o caráter textural-contrapontístico da peça I, quanto ao IDI, facilmente se veria que haveria uma ocorrência alargada dos materiais intervalares -, ou seja, muitos espaços não ocupados iguais ou maiores que uma segunda menor - percebendo-se uma predileção pelas maiores relações intervalares (melódicas e harmônicas) por uma estratégia mais harpejante ou mais rarefeita (materiais intervalo-harmônicos não densos).

Para esta análise, quando se aplicasse a partir do parâmetro DICA e, quando se falasse da densidade significativa produzida pelos intervalos de "classe 1" (Forte 1973) - lembrar-se-ia que haveria uma ressalva quanto o uso desta teoria nesta proposição analítica: ocorreria somente uma relação tangencial e não aprofundada, ou seja, não seria usado, nesta metodologia teórica, a listagem dos Forte numbers e as outras aplicações da Set Theory. Os primeiros compassos da peça I das Quatros Peças Breves já demonstrariam a condicional predileção intervalar da "classe 1". Obviamente não seria uma predileção isolada e não intencional do compositor - o que ocorreria então, seria um caminho técnicoestético que, com força máxima, representaria a maior energia da dissonância no total cromático - ou seja, este seria um recurso com potencial de vinculação à poética pós-tonal.

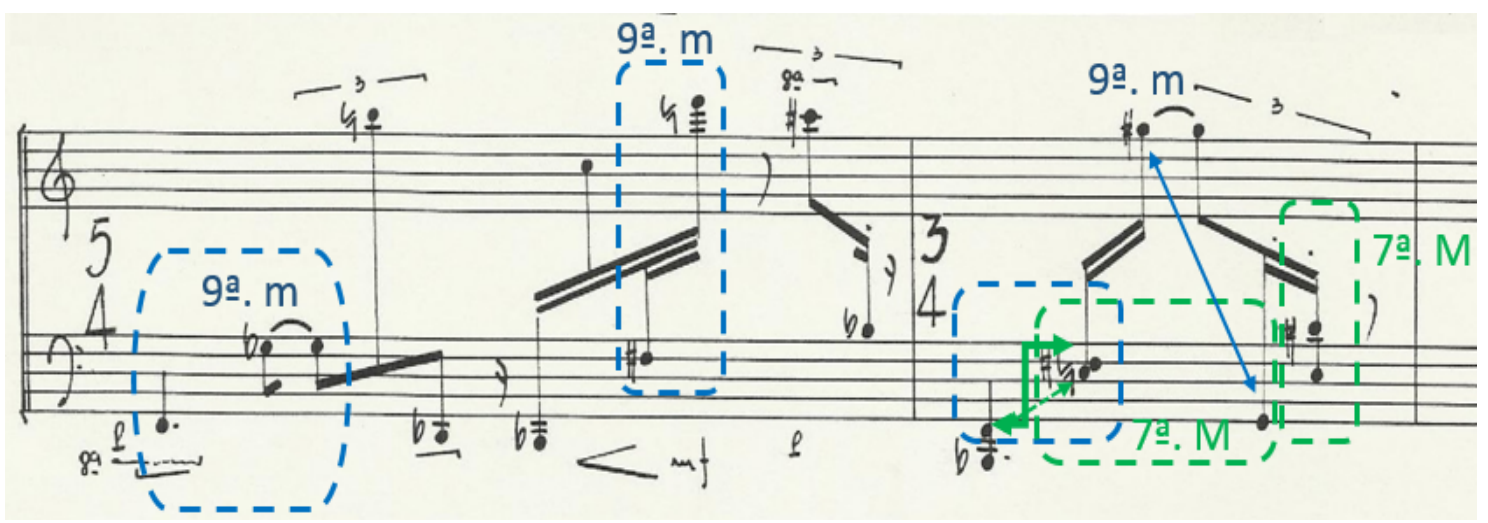

Exemplo 2: Caráter pós-tonal adquirido pelos intervalos característicos ("classe 1" do

DICA). Em azul: nona menor; em verde: sétima maior (compassos [c.] 1-2). Fonte: elaborado pelo autor

Nos compassos iniciais da peça I, como pode se ver no recorte acima ( $E x$. 2), a ocorrência dos intervalos potenciais de dissonância dura pode demonstrar 
SANT'ANA, E. H. Régua intervalar como ferramenta analítica em Quatro Peças Breves para piano de Roberto Victorio

o sentido de densidade significativa (DICA) provocado nesta rede intervalar. O mesmo tratamento intervalar pode ser observado nos Ex. 3 e 4.

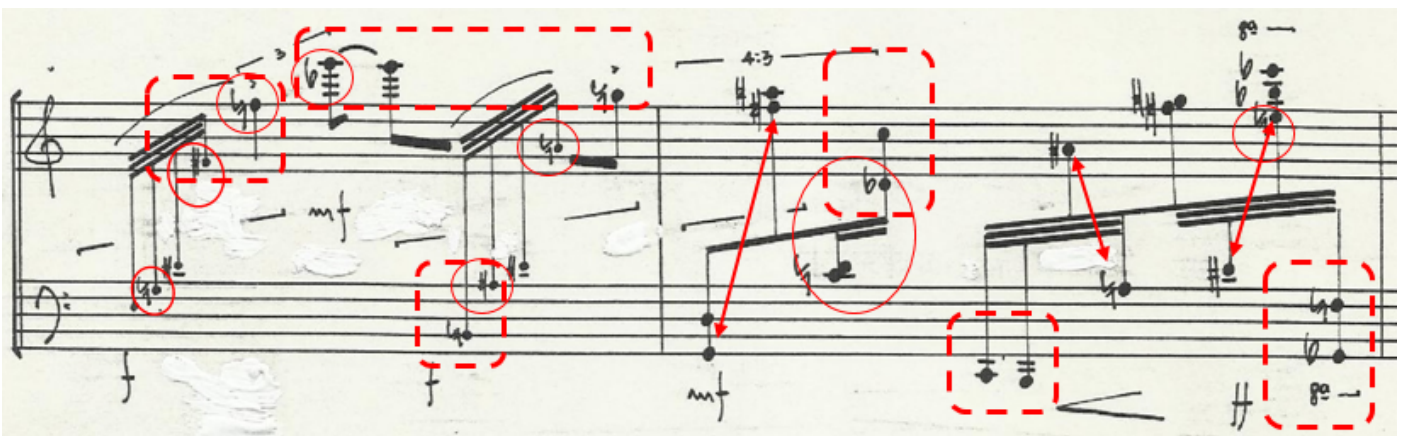

Exemplo 3: Nos cc. 5-6 da peça I, a continuidade da rede de intervalos característicos uma textura estrutural que foi mantida em toda obra das Quatro Peças Breves. Fonte: elaborado pelo autor
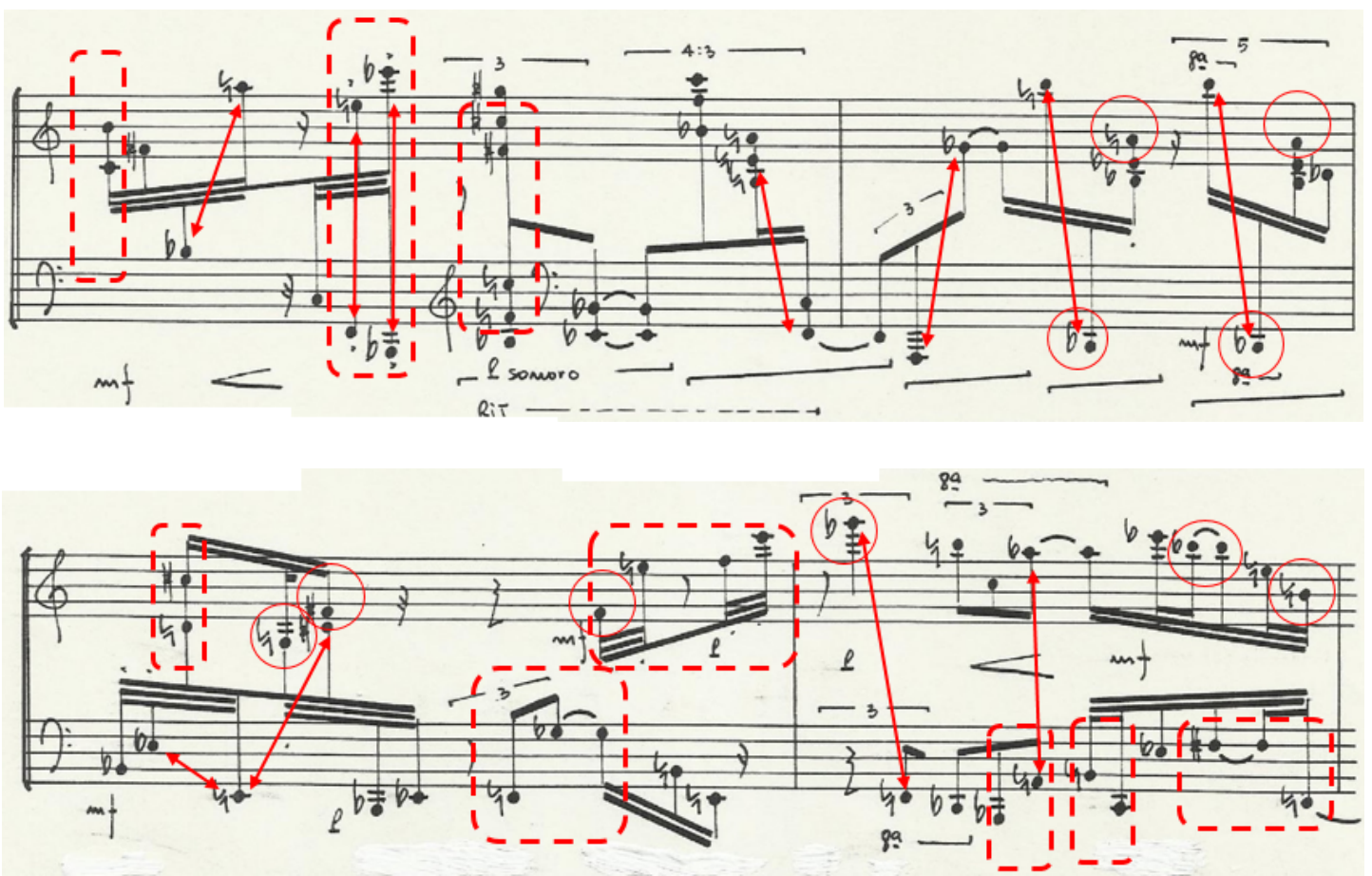

Exemplo 4: cc. 10-13 da peça I como exemplo da predominante utilização deste processo: os intervalos característicos. Fonte: elaborado pelo autor

O tratamento intervalar continuaria seguindo os mesmos moldes apresentados nos exemplos anteriores. Assim, na peça II, na peça III e na peça IV (Ex. 5) ocorreria semelhante desenvolvimento. Outro dado importante, nesta construção composicional de Roberto Victorio, seria que, o contraste e a fricção dos intervalos característicos, não aconteceriam, predominantemente, por sobreposição simples (verticalidade), mas sim por relação consecutiva, muitas 
MUSICA THEORICA Revista da Associação Brasileira de Teoria e Análise Musical 2019, v. 4, n. 2, p. 81-112 - Journal of the Brazilian Society for Music Theory and Analysis @ TeMA 2019 - ISSN 2525-5541

vezes obtida pelo alongamento da ressonância. Geralmente, como se fosse uma ideia de pedal que faria com que a sonoridade se prolongasse. Haveria sempre uma voz, um intervalo e/ou um acorde que buscaria o alongamento como uma ideia de continuidade de uma dada camada, sobrepondo algum material e, que disso, intencionalmente, resultassem as relações de intervalos potenciais de fricção (dissonância dura).

Observando-se que as relações de direcionalidade intervalar poderiam ocorrer por verticalidade, horizontalidade e/ou diagonalidade - mesmo que, também se entendesse que as duas direcionalidades principais seriam a horizontalidade e a verticalidade porque, respectivamente, elas estariam praticadas sob a justaposição e a sobreposição dos materiais. Como já foi dito, averiguou-se que, nesta obra, o compositor pareceria privilegiar as relações de horizontalidade e de diagonalidade.

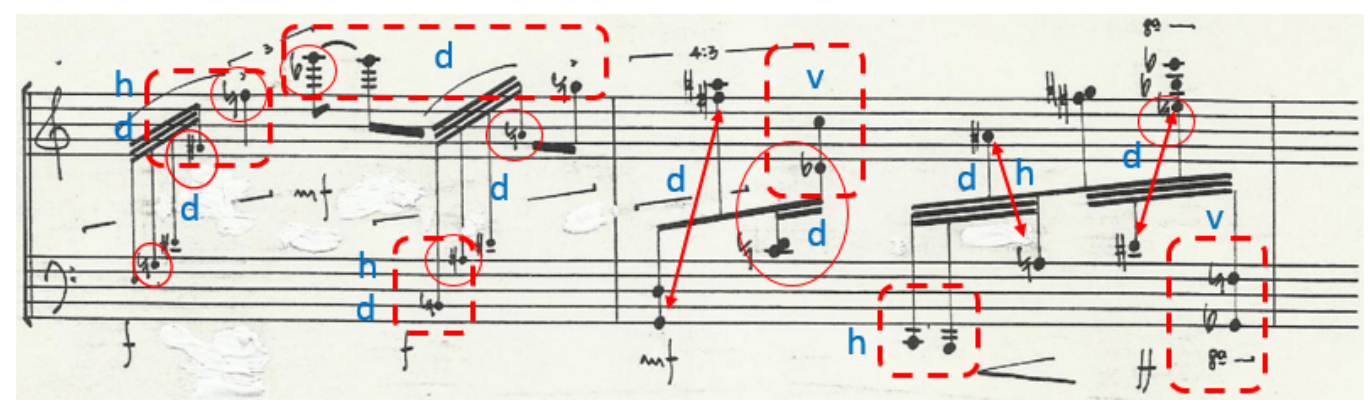

Exemplo 5: Apontamentos de várias organizações direcionais do(s) intervalo(s) característico(s): horizontalidade (h), verticalidade (v) e diagonalidade (d) (c. 5-6).

Fonte: elaborado pelo autor

Em termos práticos de consecutividade, tanto a horizontalidade como a diagonalidade seriam assemelhadas. Entretanto, as diferenças entre elas, estaria na abstração das possíveis relações intervalares pensadas na diagonalidade e/ou na ocorrência alternada de uma altura (como no primeiro caso do Ex. 5). Haveria uma certa tendência de considerar, como diagonalidade, os saltos extremamente distantes entre regiões muito mais agudas que guardassem relação mais abstrata com regiões muito mais graves. Entretanto, em contrapartida, para a horizontalidade, seriam consideradas as relações mais próximas que se equiparassem ao perfil melódico tonal e/ou aqueles passíveis da escuta mais genérica e convencional.

Em primeira instância a régua intervalar, sob o ponto de vista do parâmetro DICA, demonstra as relações que são oriundas de estruturas acórdicas que 
SANT'ANA, E. H. Régua intervalar como ferramenta analítica em Quatro Peças Breves para piano de Roberto Victorio

ofereçam uma maior evidência de escuta sonora que privilegie, com destaque, os intervalos dissonantes, no entanto, inversamente, as consonâncias, neste parâmetro, podem também ser percebidas nos seus contextos acórdico-intervalares.

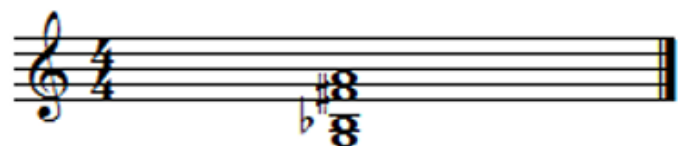

Exemplo 6: Peça II (c. 9): observação das sétimas maiores sobrepostas. Fonte: elaborador pelo autor

Entendendo a estrutura acórdico-intervalar de sétimas maiores sobrepostas do Exemplo 6 como material passível de uma escuta com potencial dissonante a priori, ainda assim, esta fricção das sétimas seria observada como uma ocorrência interna mais sutil. Ao mesmo tempo, a estrutura acórdicointervalar conteria em si duas terças menores sobrepostas (mais grave: Sol2-Si,2; mais aguda: Fá»3-Lá3). Nesta disposição, a Figura 8 ofereceria uma direção objetiva mais detalhada para levar-se em conta o fenômeno de fricção dos intervalos dissonantes frente aos intervalos consonantes.

\begin{tabular}{|c|c|c|c|c|c|c|c|c|c|}
\hline$\cdots$ & Acorde & IDI & DICA & DICA & \multicolumn{2}{|l|}{ DICA } & \multicolumn{3}{|c|}{ NÃO EXCLUSÃO DOS OUTROS } \\
INTERVALOS (CONSONANTES)
\end{tabular}

Figura 8: Régua intervalar: a interrelação dos intervalos dissonantes (intervalos característicos) com os intervalos consonantes. Ver cores referentes aos intervalos dissonantes (vermelho: DICA com IDI de densidade máxima [segunda menor - não houve ocorrência]; verde: DICA com IDI de média rarefação [houve duas ocorrências]; 
MUSICA THEORICA Revista da Associação Brasileira de Teoria e Análise Musical 2019, v. 4, n. 2, p. 81-112 - Journal of the Brazilian Society for Music Theory and Analysis @ TeMA 2019 - ISSN 2525-5541

azul: DICA com IDI de maior rarefação [não houve ocorrência]). Fonte: elaborado pelo autor

Outra potencialidade da régua intervalar é a ênfase à percepção da ocorrência das alturas presentificadas (diretas e primariamente relacionadas tracejadas em verde) e não presentificadas (indiretas e segundariamente relacionadas - em amarelo). Há conjuntamente, também, a noção da rarefação (senso das alturas não ocupadas), onde seria evidenciada pelo desenho da disposição gráfica de pontuar as diferentes possibilidades no total cromático. Assim, o que aconteceria, é a associação do parâmetro DICA (densidade significativa) à ideia da densidade real do parâmetro IDI. Quanto ao IDI, o que se perceberia, é que, a estrutura acordal acima teria uma densidade real média. O intervalo real $^{9}$ (princípio matemático de "espaço aberto") de espaços não ocupados entre as terças sobrepostas é de 7 semitons ocasionando um intervalo musical ${ }^{10}$ (princípio matemático de "espaço fechado") de uma sexta menor.

\section{Ocorrências múltiplas de clímax sonoros}

Considerando algumas classes de estruturas musicais que têm grande propensão de compor um clímax sonoro, pode-se levar em conta cinco delas - a estrutura intervalo-acórdica (harmônica), a estrutura rítmica (desenvolvimento e/ou ebulição de certas células rítmicas) associada à estrutura dinâmica aplicada ao material rítmico-harmônico (intensidades) e a estrutura máxima do parâmetro LAO (exploração das oitavas nos seus limites de máximo grave e de máximo agudo das alturas) - todas estas referências de classes de estruturas, ajudariam a

\footnotetext{
9 “[...] pensamento anteriormente descrito, o intervalo real se caracteriza pelo espaço não utilizado entre duas alturas (inexistência de qualquer nota/som). Leve-se em conta que no total cromático as unidades de semitom são doze; assim, entre qualquer segunda menor não há intervalo real ("intervalo não ocupado"). Como já foi dito, um intervalo real só ocorre a partir de intervalos iguais ou maiores que uma segunda maior. Proveniente das teorias no campo da Matemática há o conceito de "intervalo aberto" equivalente ao que proponho como intervalo real, ou seja, o intervalo fisicamente "não ocupado" (Sant'Ana 2017, p. 236).

10 “No entanto, teoricamente ao longo do aprendizado básico dos elementos da Música tem-se avaliado os intervalos e sua contagem como "intervalos fechados", como se vê na representação do exemplo a seguir. Matematicamente, conta-se o ponto $a$ (uma altura qualquer), a "distância não ocupada" e mais o ponto $b$ (uma outra altura qualquer). Da mesma forma, podemos representar essa prática comum na tradição musical, em que, as extremidades "a" (mais grave) e "b" (mais aguda), ou seja, as duas alturas de qualquer intervalo são consideradas musicalmente como pertencentes à classificação do intervalo no seu "todo" [...]" (Sant'Ana 2017, p. 237).
} 
direcionar a intenção de potencializar algum material musical que possa ser caracterizado como possuidor de um clímax, de uma energia, de um timbre harmônico. Tal preocupação visaria dar a certas montagens acórdicas um status de locus tímbrico - seriam espaços/eventos que conteriam entidades tímbricoharmônicas. Ou seja, seria um tipo de estrutura não mais buscando o caráter resolutivo da polaridade para a estrutura harmônica (como no tonalismo), mas sim, uma estrutura com certas características sonoras ligadas a uma classificação de cores ou sensações que pudessem destacar alguma ênfase, ou ainda talvez, algum brilho emergente das parciais provenientes da simultaneidade intervalar de uma dada estrutura intervalar e/ou acórdica - o timbre harmônico seria uma das características fortemente presentes na entidade harmônica.

Como exemplo, o clímax sonoro da peça I sendo demonstrado no Exemplo 7, onde a segunda estrutura intervalo-acórdica, contida na chave tracejada (em azul), é enfatizada pelo Ré\#3 que guardaria contraste sonoro (intervalo característico de segunda menor) com o Mi5 da base desta segunda estrutura intervalo-acórdica. A terceira estrutura - Sol,0-Fá1 - confirmaria o clímax sonoro com o extremo grave da estrutura máxima do parâmetro $L A O$, ou seja, esta peça I teria, neste local, sua ocorrência mais extrema quanto aos limites de tessitura (o mais grave: Sol,b-Fá1 - que contrastaria com o agudo: Mi5, Si, 5 e Mi, 6$)$. Assim, pensando-se no contexto da estrutura máxima do parâmetro da LAO, o compositor combinou a divisão rítmica do tempo por fusas à estrutura harmônica, o que se definiu acima, como estrutura rítmico-harmônica que, antes, já teria o clímax sonoro por um destaque da estrutura intervalo-harmônica. Como último dado, não menos importante, observa-se a estrutura dinâmica corroborada por um crescendo que desembocaria em um fortíssimo (ff). Mesmo que, as alturas em questão, estejam separadas como 3 eventos consecutivos (1ํ: Ré»3-Mi5; 2ํ: Mi5-Si $15-M i, 6$; 3o: Sol,0-Fá1) levando em conta a linha do tempo musical, houve uma intenção de agrupá-los sob a atribuição de clímax sonoro. 
MUSICA THEORICA Revista da Associação Brasileira de Teoria e Análise Musical 2019, v. 4, n. 2, p. 81-112 - Journal of the Brazilian Society for Music Theory and Analysis @ TeMA 2019 - ISSN 2525-5541

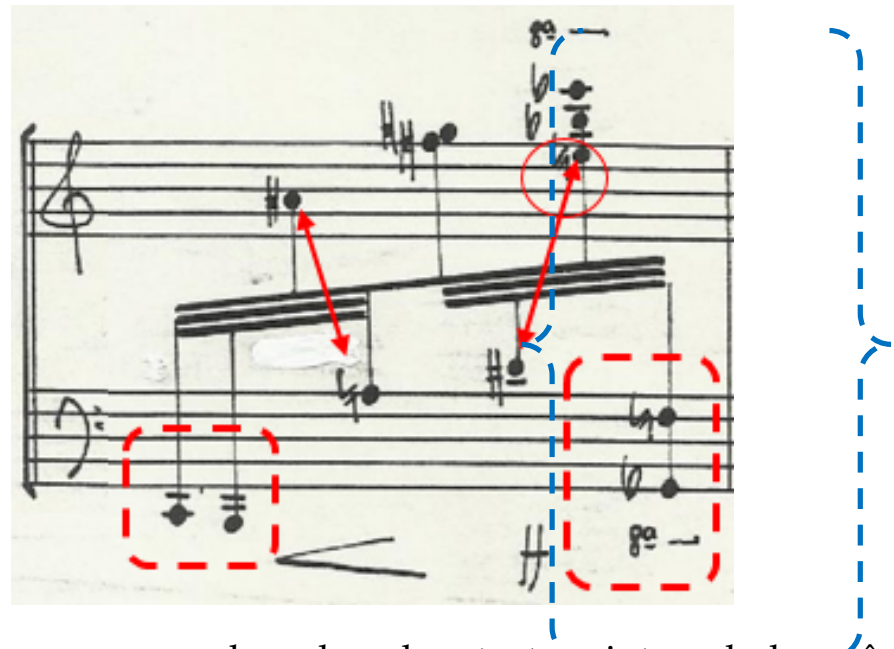

Exemplo 7: Clímax sonoro corroborado pela estrutura intervalo-harmônico e pela estrutura rítmico-harmônica combinadas à estrutura máxima do parâmetro LAO. Peça I (c. 6): gesto antecedente - Ré $¥ 3-M i 5$ (oitava aumentada); Mi5-Mi $/ 6$ (oitava diminuta = sétima maior); gesto consequente - Sol,0-Fá1 (sétima maior). Fonte: elaborado pelo autor

A estrutura em chaves azuis contém, hipoteticamente, dois gestos: um antecedente e um outro consequente. À frente se destacaria esses dois momentos rítmico-harmônicos a partir de uma análise sonológica (LAO) das alturas que guardam relações com intervalos característicos (por uma disposição vertical do antecedente).

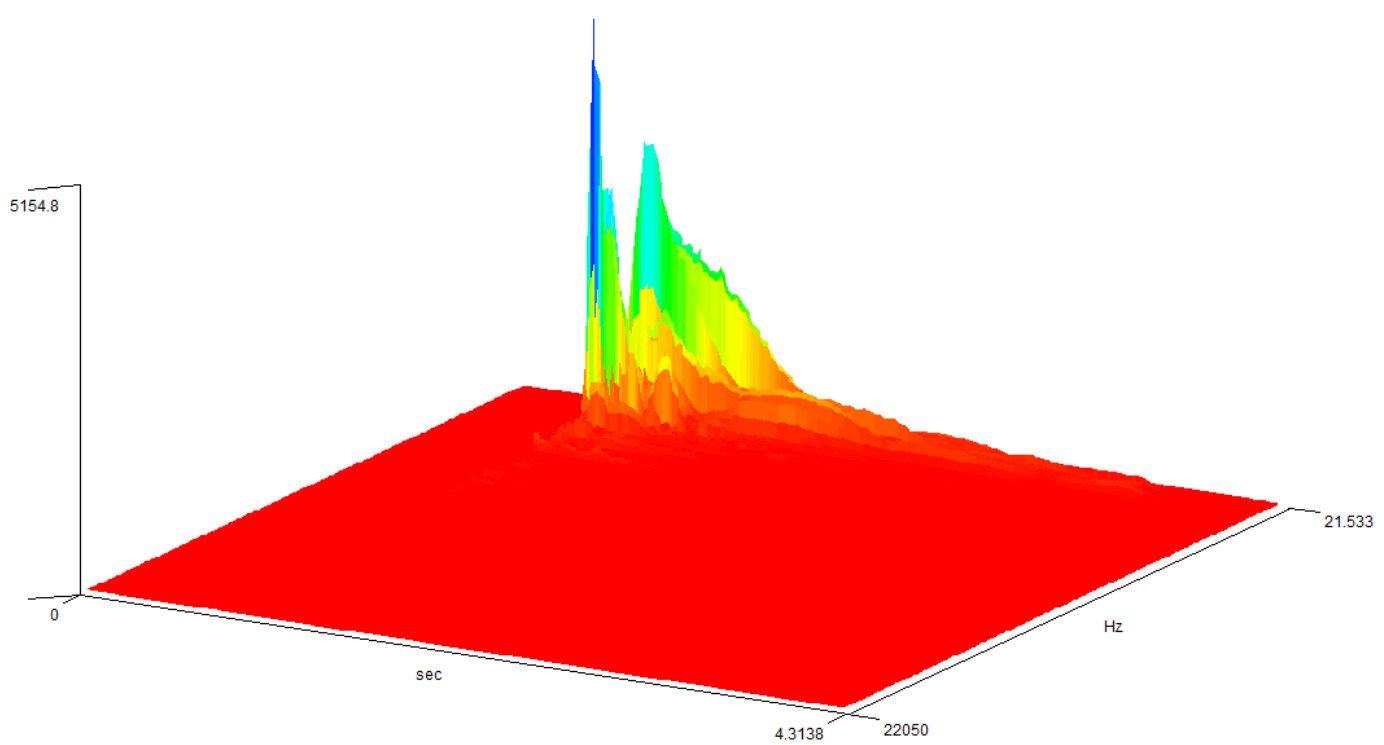

Figura 9: Gesto antecedente: Ré\#3-Mi5-Si,5-Mi,6. Quatro alturas com seus primeiros harmônicos mais destacados quanto às suas intensidades. Fonte: elaborado pelo autor.

No próximo exemplo, a Figura 10, em azul, além dos picos mais intensos dos primeiros harmônicos em questão, revelaria também outras ações menores 
SANT'ANA, E. H. Régua intervalar como ferramenta analítica em Quatro Peças Breves para piano de Roberto Victorio

de intensidade, dando assim, uma melhor ideia quanto ao agrupamento intervalar e às reverberações das parciais de cada altura envolvida. Na prática, estas alturas e suas parciais, todas pertenceriam às coleções de sons que o compositor intencionaria organizar a partir da ideia de timbre harmônico. Nestes moldes, cada altura e possíveis parciais se destacariam pela ênfase ou não que seria propiciada pela estrutura dinâmica (alcance das amplitudes do primeiro harmônico e seus subsequentes secundários corroborados com o ataque real [aftertouch] ${ }^{11}$ neste complexo que se denomina a altura [nota] da "estrutura harmônica"). Neste contexto, outros picos de intensidade poderiam provocar um destaque de outras parciais que naturalmente teriam as suas envoltórias das vibrações intensificadas quando este complexo sonoro fosse executado com maior ou menor índice geral de intensidade (volume). Tal situação seria visualmente perceptível no gráfico - uma maior ou menor ação das fundamentais seguidas da defasagem natural das suas respectivas parciais.

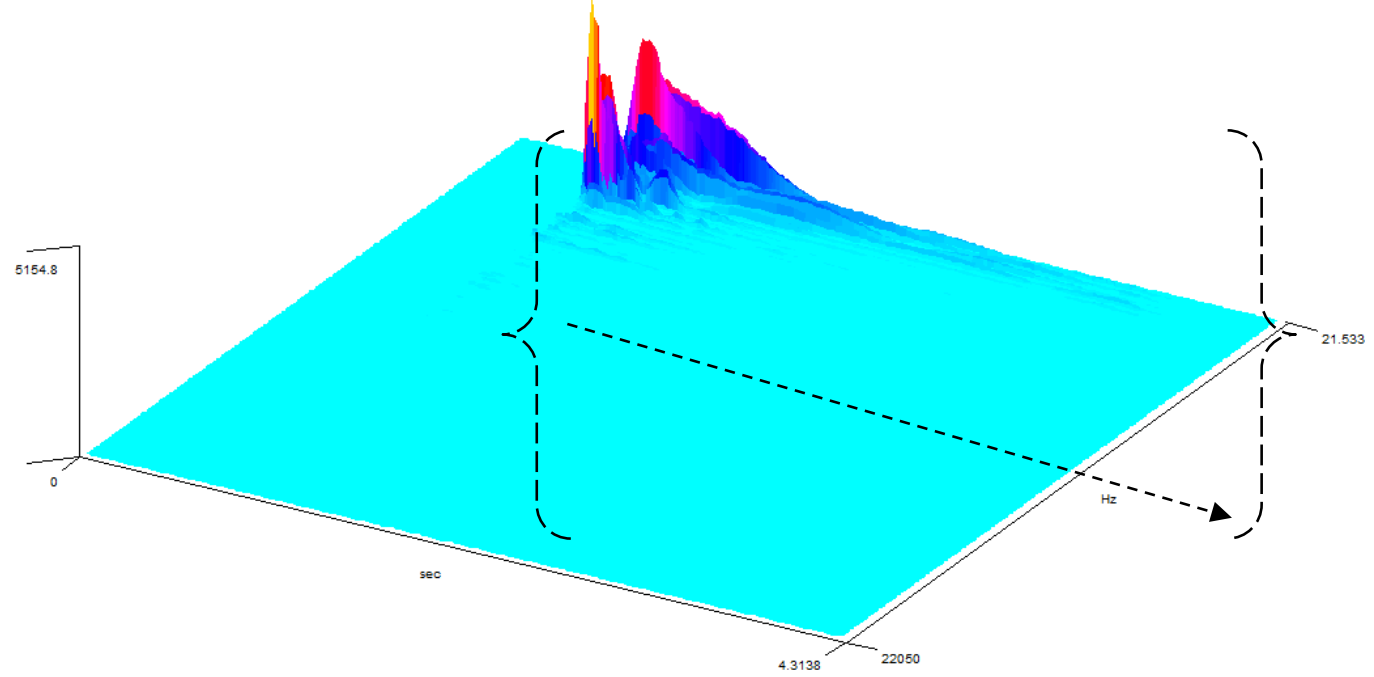

Figura 10: Observa-se o decay nas parciais secundárias: decaimento das intensidades de harmônicos secundários - podendo ser verificadas com mais atenção na seta tracejada no interior das chaves a partir da perspectiva do tempo (sec.). Fonte: elaborado pelo autor

Originalmente, o gesto consequente do compasso 6 da peça I se configuraria como uma estrutura sincrônica fazendo o papel de resposta constrastante ao médio-agudo do material antecedente. A localização da altura na oitava (LAO), como parâmetro, tem a importância de destacar os limites do grave

${ }^{11}$ Nível de pressão do toque exercido nas teclas ou nas cordas. 
MUSICA THEORICA Revista da Associação Brasileira de Teoria e Análise Musical 2019, v. 4, n. 2, p. 81-112 - Journal of the Brazilian Society for Music Theory and Analysis@ TeMA 2019 - ISSN 2525-5541

e do agudo. Pianisticamente, com tal procedimento, o compositor reforça o ápice sonoro-harmônico da peça I por uma aplicação contrastante entre as diferenças dos extremos frequenciais da escuta sonora no instrumento.

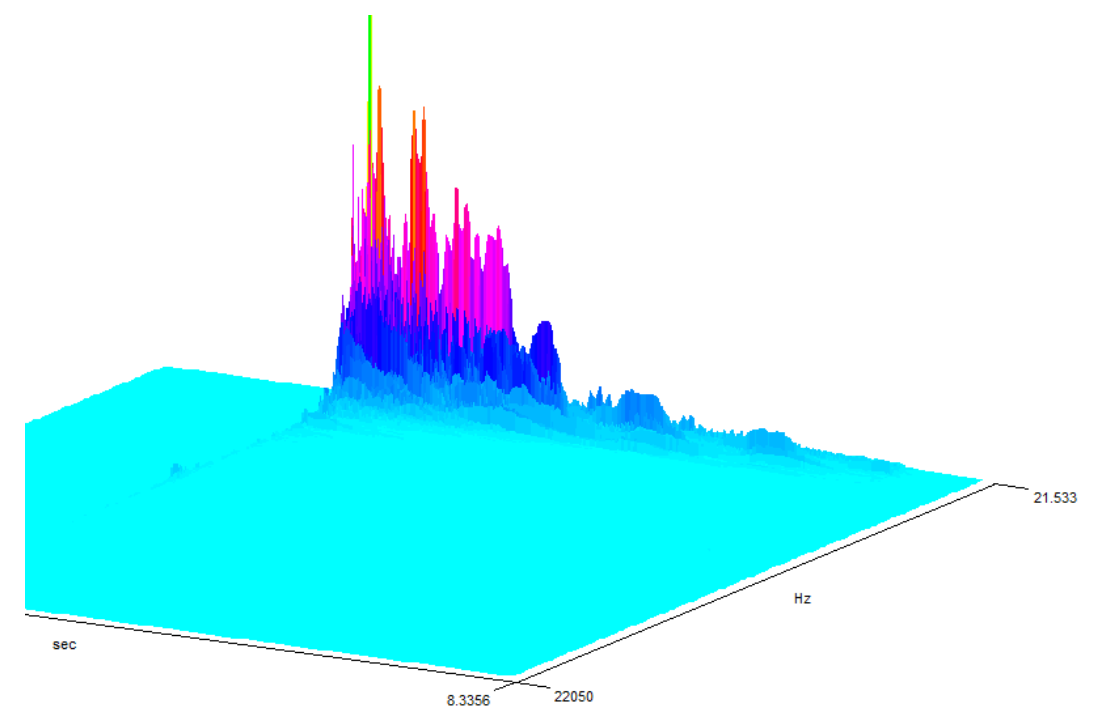

Figura 11: Gesto descendente: Sol,0-Fá1. Fonte: elaborado pelo autor

Semelhantemente, observando-se um outro possível caso de clímax sonoro, o próximo conjunto da peça II (igualmente no compasso 6), conteria duas partes (antecedente e consequente) ocorrentes, também, como ideia de antagonismo. Onde seria esperado uma estrutura intervalo-acórdica com maior densidade real nas suas alturas ocorrentes (IDI), o compositor proporia uma quebra de expectativa utilizando, unicamente, um intervalo característico de $29^{\text {a }}$ aumentada ( $8^{\mathrm{a}}$ aumentada $=$ nona menor). $\mathrm{O}$ grande alargamento do limite intervalar segue a ideia de uma ampliação da tessitura que projeta o aspecto de profundidade entre o grave e o agudo. Neste caso, a estrutura máxima do parâmetro $L A O$ é acionada por uma ênfase da estrutura dinâmica que foi indicada por um forte $(f)$.

Ainda, neste mesmo compasso 6, um outro elemento da parte 'consequente' estabeleceria um tipo de complementação rítmico-intervalar que moldaria o acabamento e a expansividade do gesto composicional deste clímax. Há um rápido desenvolvimento que combina uma ascendência do material, na parte aguda, contrastando com a descendência do material na parte grave. $\mathrm{O}$ desenvolvimento intervalar segue destacando o(s) intervalo(s) característico(s) de oitava diminuta (Si2-Si ß3) e de nona menor (Fáł2-Sol4 [Fá\#1-Sol5]) nesta parte 
SANT'ANA, E. H. Régua intervalar como ferramenta analítica em Quatro Peças Breves para piano de Roberto Victorio

consequente deste clímax sonoro da peça II. É importante que se observe os intervalos em questão, pois eles estão qualitativamente intercalados e associados com um intervalo de dissonância branda (sétima menor) e um intervalo de consonância neutra (quarta justa).

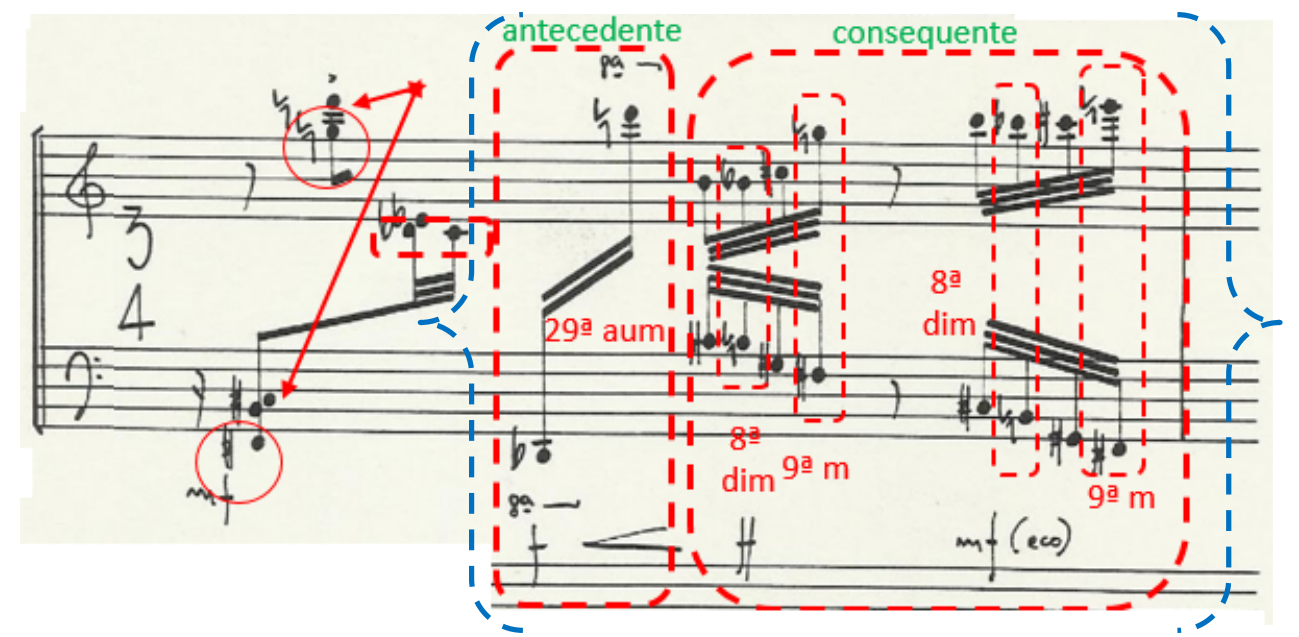

Exemplo 8: Estrutura intervalo-acórdica associada à estrutura rítmico-harmônica. Peça II (c. 6): o antecedente tem maior ênfase como estrutura máxima do parâmetro LAO, entretanto liga-se à maior ênfase da estrutura dinâmica de um fortíssimo (ff) que, logo decresce em um meioforte $(m f)$ que, ainda assim, atrela-se ao anterior elemento em $f f$ por uma ideia de eco. Fonte: elaborado pelo autor

O material antecedente do exemplo anterior (Ex. 8) ocorre, novamente, com a ideia de apresentar os limites entre o grave e o agudo. Com vistas à outra perspectiva, na próxima figura (Fig. 12), seria apresentada uma sistematização por uma Transformada Rápida de Fourier (FFT), onde seria destacada a ocorrência das parciais de cada uma das duas alturas que estão distadas de um intervalo musical de $29^{a}$ aum ( $8^{\underline{a}}$ aum). Neste ponto, novamente, a disposição temporal das alturas é desenvolvida como material justaposto como uma alusão a um intervalo melódico. Com objetivos analíticos por uma perspectiva sonológica, optou-se, então, novamente, por uma disposição sincrônica deste material (cf. Ex. 9).

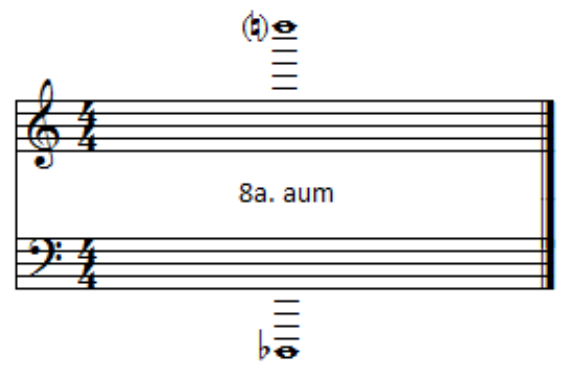

Exemplo 9: Peça II (c. 6): antecedente (Ré,0-Ré6). Fonte: elaborado pelo autor 
MUSICA THEORICA Revista da Associação Brasileira de Teoria e Análise Musical 2019, v. 4, n. 2, p. 81-112 - Journal of the Brazilian Society for Music Theory and Analysis @ TeMA 2019 - ISSN 2525-5541

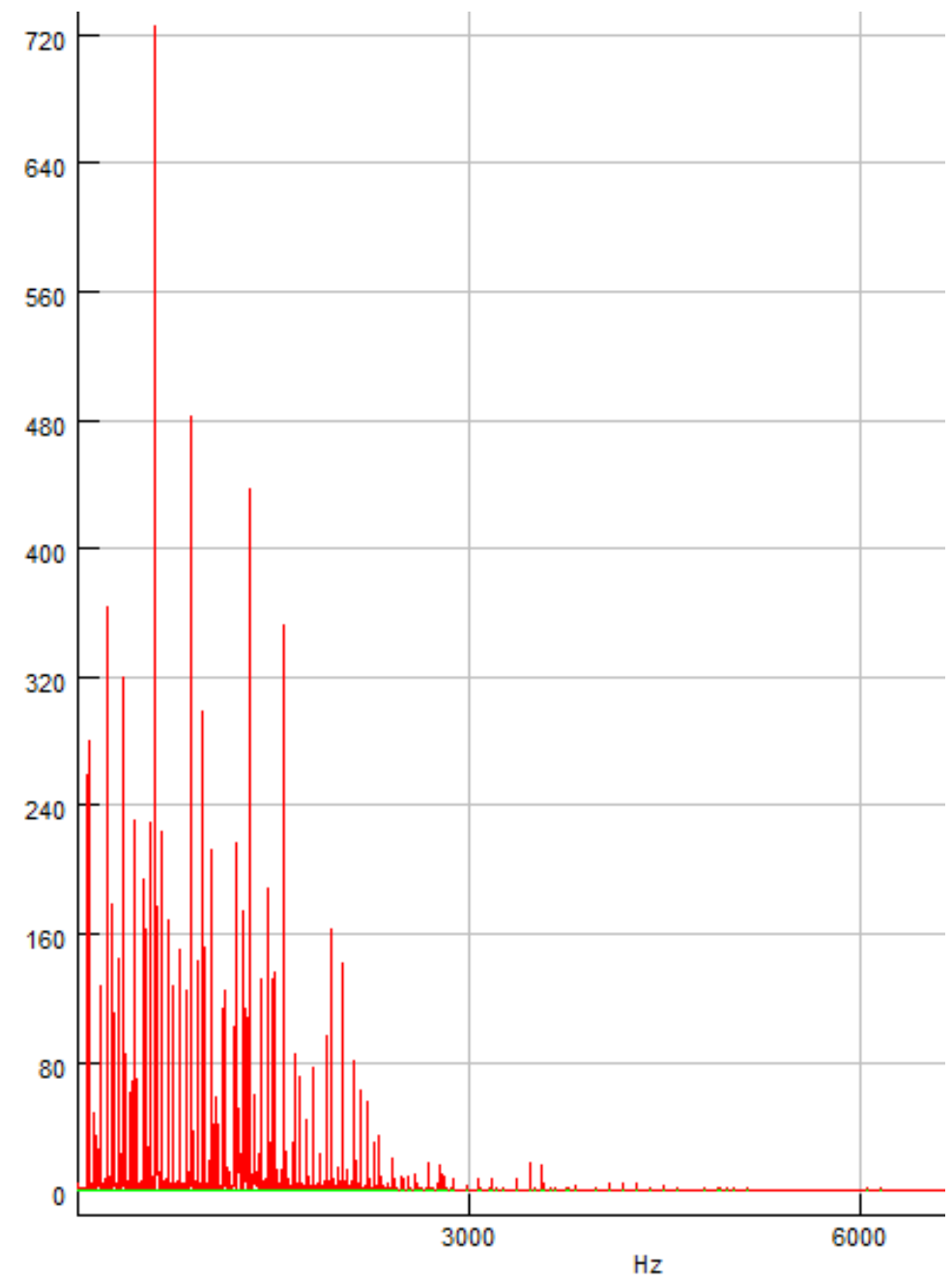

Figura 12: Peça II (c. 6): antecedente (Réb0-Ré6). Ressonância e sobreposição dos harmônicos envolvidos no intervalo característico de 29a aum. ( $8^{\mathrm{a}}$ aum.) de Réb0-Ré6: a soma de todos os harmônicos percebidos entre 34 e $2400 \mathrm{~Hz}$ ). Fonte: elaborado pelo autor

O próximo exemplo, pinçado da peça III, demonstraria os blocos ressonantes como estruturas acordais que seriam relacionados, também por fricção, por intermédio dos intervalos característicos. Assim, o compositor privilegiaria a tangência intervalar utilizando o movimento sucessivo dos materiais. Não haveria, aqui, sobreposição direta, se bem que, haveria a ideia de manter os materiais em camadas. As estruturas acórdicas aconteceriam, cada qual, na sua região e, estariam dispostas de forma que, em algum momento, haveria a interrelação dos intervalos em questão - pelo menos em um sentido de diagonalidade abstrata - entendendo que esta 'suposta horizontalidade inclinada' pudesse ser compreendida pela possibilidade de se executar alturas diferentes e mais extremas numa sucessão temporal. 
No próximo exemplo, a inflexão de um Si5 que contrasta com os materiais das outras camadas no aspecto de ocorrência de sons como frequências: aguda (o próprio Si5), média (Fá\#m sus9 e Lá sus9 alternados) e grave (Si b sus4/Dó por uma relação diagonal pensada como outra camada) - cada estrutura, nestas regiões, seria parte de uma coleção tímbrica -, assim, tais estruturas acórdicas representariam essas diferenças de cor que o material proporcionaria em diferentes níveis frequenciais (em suas camadas). Em especial, na região mediana, a camada traria um movimento de dois acordes com quintas sobrepostas nesta disposição: Fá\#3-Dó\#4-Sol\#4 e Lá3-Mi4-Si4 (o movimento de duas quintas justas sobrepostas na mesma direção [quintas paralelas] - algo bem típico da sonoridade de obras contemporâneas). No Exemplo 10, as setas em vermelho sempre apontariam alguma ocorrência de algum intervalo característico.

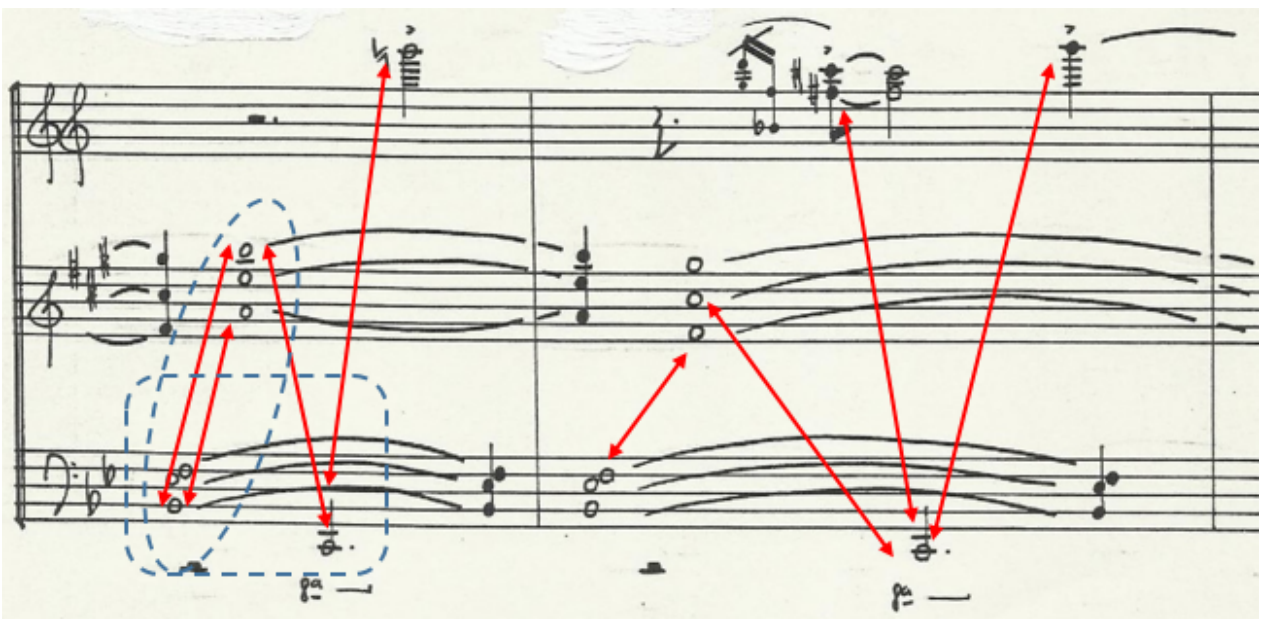

Exemplo 10: Sons distribuídos em camadas grave, média e aguda que distam por intervalo característico (ver setas). Peça III (cc. 9-10): Lá sus9 sobre Sib sus4/Dó. Fonte: elaborado pelo autor

Há um cuidado na imbricação e na organização do intervalo característico que acrescentaria uma potencialização da energia sonora nestas formações acórdicas resultando em coleções tímbricas. Para tanto, com intuito de se observar o fenômeno intervalar-harmônico, pinçou-se uma 'amostra abstrata' originalmente, estando numa direcionalidade diagonal na composição, sendo, de fato, analisada aqui, por uma direcionalidade vertical - assim, auditivamente, poderia afirmar-se, talvez, que a amostra pinçada, como uma das mais sobressalentes, remete-nos às coleções sonoras de Debussy. $O$ acorde, em questão, consistiu de um Lá sus9 sobre um acorde de Sib sus4 (ideia de camada) 
MUSICA THEORICA Revista da Associação Brasileira de Teoria e Análise Musical 2019, v. 4, n. 2, p. 81-112 - Journal of the Brazilian Society for Music Theory

- uma sobreposição acórdica com um caráter de bloco sonoro. Cada parte desta estrutura total e abstrata conteria três sons. O Lá sus9 seria composto por Lá3, Mi4 e Si4 e o Sib sus4 por Sib1, Mib2 e Fá2 - todas estas duas estruturas tonais acórdicas sobrepostas resultariam num contraste e numa fricção de intervalos característicos. Um jogo intervalar, intencionalmente, bem pensado, onde, na composição teria uma direcionalidade diagonal das relações entre os materiais.

Prosseguindo nesta visão analítica, a estratégia de particionar e, depois, comparar cada uma destas duas estruturas acórdicas que foram, artificialmente, sobrepostas (Lá sus9/Sib sus4) com fins de se perceber a fricção dos intervalos característicos e a pós-relação das ressonâncias dos harmônicos que cada uma das alturas/notas possuiria, assim, a posteriori, a partir das fundamententais destas seis alturas (Sib1, Mib2, Fá2, Lá3, Mi4 e Si4) - sobrepondo-se as ressonâncias de cada uma destas fundamentais. Como parte das primeiras instâncias da aplicação da LAO, o estudo da forma de onda pode apontar a atenuação das amplitudes das parciais subsequentes de cada nota do acorde sobreposto de Lá sus9/Sib sus4 (6 notas sincrônicas).

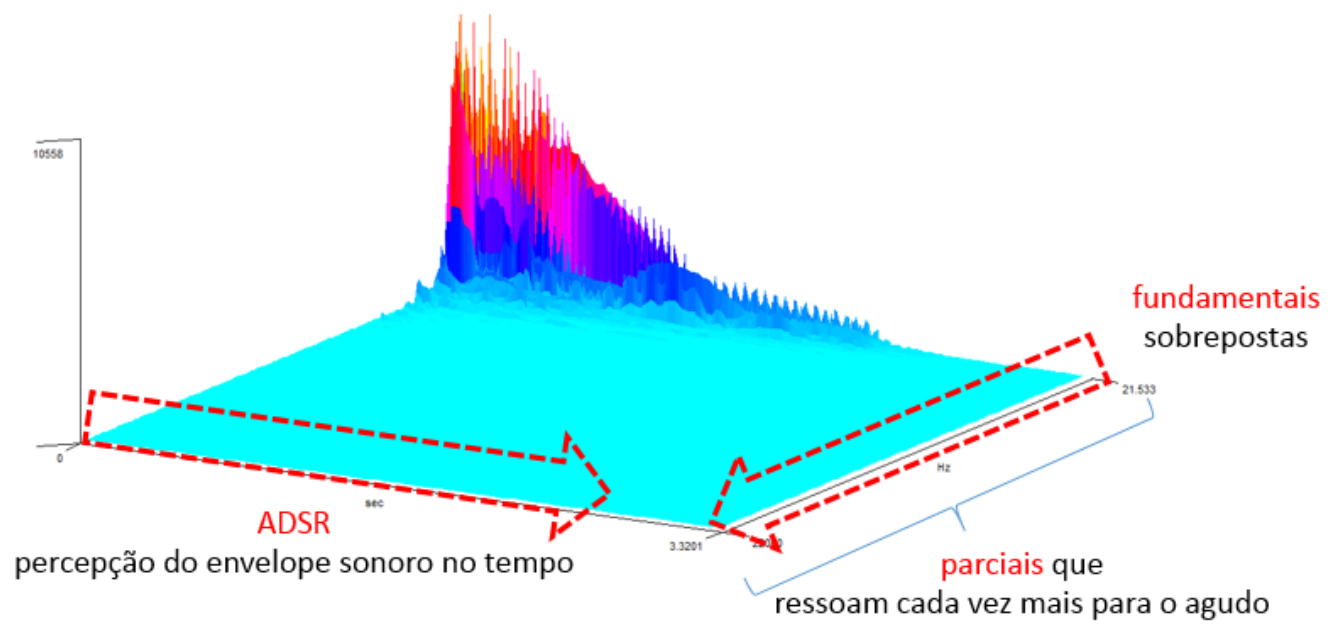

Figura 13: Massa sonora geral da estrutura acórdica Lá sus9/Si, sus4. Um recorte tridimensional: A (Ataque), D (Decaimento), S (Sustentação) e R (Relaxamento) parâmetros que se relacionariam à amplitude em função do tempo. Os seis sons relacionados ([Si „1, Mi ,2, Fá2, Lá3, Mi4 e Si4] e seus harmônicos), todos eles ficariam relacionados em sobreposição - resultando num comparativo que demonstraria também a massa sonora final (frequência [HZ] e amplitude). Fonte: elaborado pelo autor

Recordando que, para Helmholtz (1885) a descrição espectral de um som possuiria a correlação mais direta com o seu timbre, assim, mais à frente, e, a 
Régua intervalar como ferramenta analítica em Quatro Peças Breves para piano de Roberto Victorio

partir de Loureiro e De Paula (2006) quando num estudo analítico-sonoro ${ }^{12}$ sobre os timbres variados do clarinete relacionaram diversas amostras, eles disseram que: "As amostras foram obtidas a partir de gravações de alta qualidade de todas as notas dos dois registros mais graves da Clarineta em Si b, variando de Ré 3 (147 $\mathrm{Hz})$ a Lá $5(880 \mathrm{~Hz})$, executadas nos quatro níveis de intensidade [...] [pp, mp, mf e ff], com uma duração média de 3 segundos" (Loureiro e De Paula 2006, p. 61). Sabendo que esta pesquisa fosse referente à timbrística específica do clarinete, $\mathrm{o}$ estudo de Loureiro e De Paula (2006, p. 64) estabeleceram alguma diretriz no sentido de se atentar aos primeiros, terceiros e quintos harmônicos como preponderantes na formação sonora de uma altura musical pensada como entidade tímbrica. Nestes termos, os próximos avanços analíticos, utilizando a LAO, deveriam ocupar-se do estudo destas parciais em cada altura que pudesse compor algum conglomerado harmônico atonal identificado e/ou escolhido a partir de um colorido tímbrico sobressalente e/ou destacado, no ato da escuta, o qual, como já repetidamente, tem-se denominado como clímax sonoro.

Nesta direção, Sant'Ana (2017, p. 427, grifo nosso) teria descrito tal processo como uma intenção de "imprimir o controle dos ápices expressivos da obra por meio de uma ideia [...] [denominada de] um grifo sonoro." Nesse sentido, também, o conceito de "formante tímbrico" de Flo Menezes (2013, p. 133) pareceria corroborar quando o mesmo explicaria a busca pela poética que enfatizasse, em uma composição, certos locais que devessem ser evidenciados com uma maior ou menor densidade sonora - onde, seria chamada de tímbrica.

Desta maneira, quando se criou a régua intervalar (IDI, DICA e LAO) ${ }^{13}$ como instrumento que identificaria o(s) intervalo(s) característico(s), toda esta

\footnotetext{
${ }^{12}$ Um dos objetivos do estudo de Loureiro e De Paula (2006) foi fazer comparações com amostras originais do clarinete e amostras de sons ressintetizados com objetivo de avaliar se os ouvintes reconheceriam diferenças capitais entre os sons originais do clarinete e os sons ressintetizados que imitariam e/ou representariam os sons originais do clarinete. Ao final dos testes auditivos, as diferenças não foram sentidas pelos ouvintes, neste caso aceitando-os como semelhantes. Com isso o estudo comprovou que é possível estudar as características da fundamental e as suas parciais e reproduzi-las com similaridade objetivando algum tipo de controle e/ou estudo teóricoanalítico do timbre.

${ }^{13}$ Assim, a partir de cada fundamental de uma nota representada no total cromático na escrita, esta mesma seria uma raiz aparente de outras parciais ressonantes. A isso, implicaria perceber o controle tímbrico pelo cuidado de uma poética expansível - sendo um tipo de música eletroacústica, sem, necessariamente, ser música eletroacústica na sua forma ipsis litteris.
} 
MUSICA THEORICA Revista da Associação Brasileira de Teoria e Análise Musical 2019, v. 4, n. 2, p. 81-112 - Journal of the Brazilian Society for Music Theory and Analysis@ TeMA 2019 - ISSN 2525-5541

conjuntura teórico-analítica contribuiria para um entendimento mais global da estratégia que certos compositores aplicariam por meio de determinadas ênfases sonoras quando quiseram impor um clímax estrutural. Haveria a possibilidade da ocorrência de um ou mais pontos de grifos sonoros com papel de ênfase expressiva (Sant'Ana 2017, p. 427). Nesta poética tímbrica seriam uma ou mais regiões onde ocorreriam espaços estruturais a serem mais destacados. Poderia ocorrer a atomização destes pontos de referência tímbrica em determinadas obras, sempre tendo como agentes pontuais e materiais - o(s) intervalo(s) característico(s) - que, em suas montagens e organizações poderiam ser mais ou menos densos (IDI).

\section{Algumas conclusões}

A régua intervalar composta pelos seus três parâmetros - índice de distância intervalar (IDI), densidade intervalar por classe de altura (DICA) e localização da altura na oitava (LAO) - visa oferecer contribuições no estudo teórico-analítico dos repertórios modernos e contemporâneos que se utilizem do ambiente do total cromático. A LAO oferece a possibilidade de avançar-se na compreensão que considera a nota escrita (notas musicais como som fundamental) e os aspectos de ressonância das parciais desta fundamental. Nestes termos, esta ferramenta poderá alcançar outros repertórios que dão importância ao timbre harmônico ${ }^{14}$ do material composicional como aqueles também contidos na escola francesa do século XX (Satie, Varèse, Debussy, Stravinsky, Messiaen e Boulez).

O parâmetro LAO (densidade sonológica), além de oferecer potencial de análise do som em si, estabeleceria a direta ligação dos aspectos da densidade real (IDI) com os aspectos da densidade significativa ${ }^{15}$ (DICA) de um conglomerado acórdico. Pela ótica deste último parâmetro (DICA), aqueles intervalos que possuíssem um tipo de dissonância dura, seriam tendentes a buscar algum tipo de resolutividade tonal e/ou de alguma acomodação quanto à escuta orgânica. Assim, quando estas dissonâncias não fossem satisfeitas, quanto à índole resolutiva, tais estruturas intervalo-harmônicas seriam classificadas,

\footnotetext{
${ }^{14} \mathrm{O}$ estudo do timbre harmônico passa pela análise das parciais em todas as perspectivas (amplitude, tempo e frequência). Prioritariamente, consistiria em 'escutar' as ações dos três ou quatro harmônicos posteriores à fundamental.

${ }^{15}$ A densidade significativa envolve a questão das polaridades e apolaridades dos intervalos.
} 
caracteristicamente, ao que se tem denominado como música pós-tonal. Nesse viés, a obra Quatro Peças Breves para piano de Roberto Victorio mesmo que, não fosse uma composição carregadamente "densa" (IDI) quando se falasse de grandes clusters, ainda assim, a sua música pode ser posicionada sonoramente à poética moderna da não resolutividade polar de compositores como Messiaen, Boulez, Stockhausen, Berio, Pousseur e Almeida Prado. Do ponto de vista analítico, os três parâmetros corroboraram uns com os outros no sentido de oferecerem dados estatísticos e interpretativos que caminharam na direção desta comprovação na obra deste compositor.

Nesse sentido, conclusivamente, quando se pretendeu aplicar este conjunto de parâmetros (IDI, DICA e LAO), em outras obras que não fossem as composições de Almeida Prado (Sant'Ana 2017), como primeiro estudo experimental em obra de outro compositor, este trabalho pareceu ter alcançado um resultado satisfatório. Haveria, então, uma confirmação positiva daquela intenção de se verificar, por esta régua intervalar, quando tentou-se estudar as potencialidades energéticas dos intervalos dissonantes em relação aos consonantes. Sabendo-se que, os intervalos dissonantes, na poética pós-tonal, receberiam um status de predileção, ainda assim, o êxito desta aplicabilidade aconteceria em função do reconhecimento destas estruturas intervalo-acórdicas serem oriundas e estarem vinculadas ao background tonal (referência perceptiva da audição orgânico-musical), como foi o caso das Quatro Peças Breves.

Desta maneira, a pretensão de se avançar nos estudos que compreendam as diferentes entidades intervalo-acórdicas que formariam possíveis coleções sonoras de uma obra na pós-tonalidade, e como elas poderiam e deveriam ser reconhecidas, significaria produzir ferramentas que pudessem mensurar a potencialização resultante da fricção e da relação contrastante dos intervalos dissonantes nesta coexistência junto aos intervalos consonantes em duas perspectivas: a do total cromático e a das parciais de cada nota executada neste ambiente do total cromático. Pensando nesta direção, outrossim, o total cromático seria a condição referência-limite estético-poética que, plausivelmente, direcionaria a aplicabilidade da régua intervalar (IDI, DICA e LAO).

Nestas condições, seria possível ampliar o processo e a visão analítica sobre muitos repertórios da música pós-tonal quando se pudesse, como foi prenunciado neste estudo, averiguar as parciais de cada altura de um conglomerado harmônico, podendo tais parciais serem analisadas quanto aos 
seus respectivos formantes (tempo, frequência e amplitude). A identificação de cada amostra acordal, com maior precisão, sob o conceito de timbre harmônico como elemento edificante e identificante dos blocos sonoros -, possibilitariam a enumeração e a classificação destes mesmos blocos que, como estruturas diferenciadas poderiam cumprir os 'destaques sonoros' com a ideia de clímax nas obras modernas e contemporâneas. Lembrar-se-ia que esta proposição teórico-analítica estaria profundamente ligada à escuta e à valorização da performance como atividades reificantes da composição - mesmo que, tivéssemos que considerar a gravação como uma possibilidade abstrata e/ou do registro da performance. Quanto ao parâmetro LAO, para os próximos estudos, haveria, também, a necessidade da continuidade de averiguações mais predominantes de amostras das estruturas acórdicas sob a perspectiva da Transformada Rápida de Fourier (FFT) que, ainda assim, conseguissem preservar a íntima ligação com a lógica teórico-musical.

\section{Referências}

1. Caetano, Marcelo Freitas. 2006. Síntese sonora auto-organizável através da aplicação de algoritmos bio-inspirados. Dissertação (Mestrado em Engenharia Elétrica e em Computação). Programa de Pós-Graduação da Faculdade de Engenharia Elétrica e de Computação, Universidade Estadual de Campinas, Campinas, 2006.

2. Costère, Edmond. 1954. Lois et styles des harmonies musicales. Paris: Presses Universitaires de France.

3. 1962. Mort ou transfigurations de l'harmonie. Paris: Presses Universitaires de France.

4. Forte, Allen. 1973. The structure of atonal music. New Haven: Yale UP.

5. Guigue, Didier. 2011. Estética da Sonoridade: a herança de Debussy na música para piano do século XX. São Paulo: Perspectiva.

6. Helmholtz, Hermann von. 1885. On the Sensations of Tone. London: Longman.

7. Menezes, Flo. 2013. Matemática dos Afetos: tratado de (re)composição musical. São Paulo: Editora da Universidade de São Paulo.

8. Ogasawara, Angélica Soares. 2008. Reconhecedor de notas musicais em sons polifônicos. Tese (Doutorado em Engenharia Elétrica). Departamento de Eletrônica e Computação, Escola Técnica, Universidade Federal do Rio de 
Janeiro, Rio de Janeiro, Disponível em: <http://www02.smt.ufrj.br/ sergioln /theses/bsc18angelica.pdf>. Acesso em: 23 mai 2016.

9. Sant'Ana, Edson Hansen. 2017. A concepção intervalar em Almeida Prado: um estudo em três obras pós ruptura. Tese (Doutorado em Música). Programa de Pós-Graduação em Música, Instituto de Artes, Universidade Estadual Paulista "Júlio de Mesquita Filho", São Paulo.

10. Straus, Joseph Nathan. 2000. Introduction to post tonal theory. 1990. 2a. ed. Upper Saddle River, New Jersey: Prentice-Hall.

11. 2013. Introdução à teoria pós-tonal. 1990. Trad. Ricardo Mazzini Bordini; rev. e consultoria técnica: Jamary Oliveira; prefácio: Ilza Nogueira. São Paulo: Editora UNESP; Salvador: EDUFBA.

12. Xenakis, Iannis. 1992. Formalized Music: Thought and Mathematics in Composition. New York: Pendragon Press. 